\title{
¿Puede un antropoide generar una oración?
}

\section{H. S. Terrace, L. A. Petitto, R. J. Sanders, T. G. Bever}

FUENTE: Science, 1979, vol. 206, n. ${ }^{\circ} 4421$, págs. 891-902.

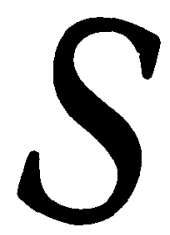

Resumen. Se analizaron más de 19.000 locuciones de varios signos de un chimpancé de corta edad (Nim), en busca de regularidades sintácticas y de semánticas. Las regularidades léxicas se observaron en el caso de las combinaciones de dos signos: determinados signos (por ejemplo, más) tendían a aparecer en una posición concreta. Estas regularidades no podían atribuirse a la memorización o a los hábitos de posjción, lo que hace pensar en una restricción estructural. Esta conclusión, sin embargo, se rechazó al analizar la grabación video, que mostraba cómo la mayoría de las locuciones de Nim se apoyaban en la locución anterior de su maestro, y que Nim interrumpía a sus maestros mucho más que un niño el lenguaje del adulto. Las expresiones de signos de otros antropoides (como muestran las películas) revelaban pautas similares de diálogo no humano.

Los estudios innovadores de los Gardner (1-3) y de Premack (4-6) demuestran que el chimpancè (Pan troglodytes) puede aprender un considerable vocabulario de «palabras» de lenguajes visuales. Los Gardner enseñaron a Washoe, una chimpancé de corta edad, signos del American Sign Language (ASL) $(7,8)$. Premack enseñó a Sara, una hembra joven, un lenguaje artificial con fichas de plástico de diferentes colores y formas. En un estudio reciente, Rumbaugh et al. (9) enseñaron a Lana, otra chimpancé joven, a utilizar el yerkés (lenguaje visual artificial). Estos estudios y otros del mismo tipo (10), en uno de los cuales se comunica la adquisición de más de 400 signos de ASL por una gorila joven llamada Koko (11), demuestran que el cambio de un medio vocal a uno visual puede compensar de forma efectiva la incapacidad que tienen los antropoides de articular muchos sonidos (12). Esta limitación bastaría, por sí sola, para explicar los fracasos anteriores de la enseñanza de la comunicación con palabras habladas en los chimpancés (13).
El lenguaje humano utiliza dos niveles estructurales: la palabra y la oración. El significado de una palabra es arbitrario frente al carácter rígido de las diversas formas de comunicación animal. Por ejemplo, muchas especies entre las aves tienen un canto para el malestar, otro para cortejar a un congénere y un tercero para delimitar el territorio. Esta rigidez es típica de la conducta comunicativa de otros géneros, como es el caso de las abejas que informan de la situación y calidad del alimento, o de los gasterósteos durante la conducta de cortejo (14).

El lenguaje humano se distingue principalmente por un segundo nivel estructural que abarca la palabra - la oración (15). Una oración expresa característicamente una proporción semántica completa mediante un conjunto de palabras y frases, cada una de ellas con una determinada relación gramatical con las otras (tal como actor, acción, objeto). A diferencia de las palabras la mayoría de las oraciones no pueden aprenderse una a una. Los psicólogos, los psico- 


\section{Estudios}

lingüistas y los lingüistas están de acuerdo en afirmar que la utilización de un lenguaje huma. no supone el conocimiento de una gramática. ¿De qué otta manera podría explicarse la capacidad esencial del niño de crear un número indeterminado de sentencias significativas a partir de un número finito de palabras?

Las demostraciones recientes de que los chimpancés y los gorilas pueden comunicarse con los hombres mediante «palabras» arbitrarias plantean una cuestión controvertida: la capacidad de crear y comprender oraciones ¿es exclusivamente humana? Los Gardner $(1,3)$, Premack (6), Rumbaugh (9) y Patterson (11) han propuesto, cada uno por separado, que las secuencias de símbolos que los póngidos pueden producir y comprender están regidas por reglas gramticales. Los Gardner, por ejemplo, piensan que «los resultados más significativos del Proyecto Washoe tienen por base las comparaciones entre Washoe y los niños, como ocurre... en el uso del orden de las primeras oraciones» (3, pág. 73).

Si un antropoide pudiera realmente crear una oración, existiría una fundamentación para afirmar, como hace Patterson (11), que ael lenguaje no es desde este momento patrimonio exclusivo del hombre». El propósito de este artículo es valorar tal afirmación; para ello expondremos brevemente los rasgos principales de un extenso cuerpo de datos que hemos obtenido de un chimpancé expuesto al lenguaje de signos durante los cuatro primeros años.

El componente principal de estos datos es el primer corpus de locuciones de varios signos en un antropoide. Superficialmente, gran parte de estas locuciones parecen oraciones. Sin embargo, el análisis objetivo de nuestros datos no proorcionó pruebas de la capacidad de los antropoides para utilizar la gramática. La supuesta competencia gramatical podrá explicarse adecuadamente en cada caso mediante procesos no lingüísticos sencillos.

\section{Proyecto Nim}

Nuestro sujeto fue un chimpancé macho, Neam Chimpsky (Nim, para abreviar) $(16,17)$. Desde que tenía dos semanas Nim se crió en un hogar con padres adoptivos humanos y maestros que se comunicaban entre ellos y con él en ASL $(7,8)$. Se le enseñaron los signos por un método desarrollado a partir de las técnicas que los Gardner (2) y Fouts (18) han denominado moldeamiento (molding) y guía (guidance). Nuestros métodos de recogida de datos fueron semejantes a los utilizados en los estudios de desarrollo del lenguaje en niños (19-24). Durante sus sesiones con Nim, los maestros susurraban en una pequeña grabadora los signos que hacía y si eran espontáneos, inducidos, moldeados o bien aproximaciones a un signo correcto (25).

Nim alcanzaba nuestro criterio de adquisición de un signo cuando: Primero, tres observadores independiente, en distintas ocasiones, constataban su aparición espontánea y, segundo, ocurría espontáneamente durante cinco días seguidos. Por espontáneo queremos dar a entender que Nim emitía el signo en un contexto apropiado y sin necesidad de moldeamiento (molding), ayuda (prompting) o modelado (modeling) por parte del maestro. Hasta el 25 de septiembre de 1977 Nim había adquirido 125 signos (20).

\section{Combinaciones de signos}

Los análisis que hacen los Gardner de las combinaciones de signos de Washoe impiden estudiar su estructura gramatical. Salvo dos excepciones de menor importancia, los Gadner no especifican el orden de los signos en las combinaciones (27). Por ejemplo, más cosquillear y cosquillear más se consideran, en los dos casos, como más cosquillear, que es el orden convencional de estos signos en inglés. Por consiguiente, no hay base para determinar si las combinaciones de varios signos de Washoe se regían por reglas de orden (28). Podrá concluirse que Washoe había aprendido que lo mismo más que cosquillear eran formas apropiadas de pedir que se repitieran las cosquillas y que, si Washoe realizaba los dos signos se debía al aprendizaje anterior de la emisión de cada signo por separado.

Definimos la combinaión de signos como la aparición de dos o más signos distintos, no interrumpidos por ninguna otra conducta o por el retorno de las manos a una posición de reposo (29). El 95 por 100 de las combinaciones de Nim consistían en secuencias de signos distintos que tenían lugar sucesivamente; se las denominó «secuencias lineales». No se incluyeron en el corpus otros dos tipos de combinaciones: las contracciones de dos o más signos y las combinaciones simultáneas de dos signos distintos. Aunque estas combinaciones son posibles en ASL, se excluyeron de nuestro corpus porque era imposible especificar el orden temporal de los signos incluidos en ellas. La Figura 1 muestra una combinación lineal típica, a mi abrazar gato, en la cual no hay solapamiento temporal entre ninguno de los signos.

En ningún caso se reforzaron diferencialmente secuencias específicas, contracciones o combinaciones simultáneas. En realidad, nunca se exigió a Nim que emitiera combinaciones de signos en lugar de signos aislados. Sin embargo, los maestros de Nim realizaban a menudo signos en un 

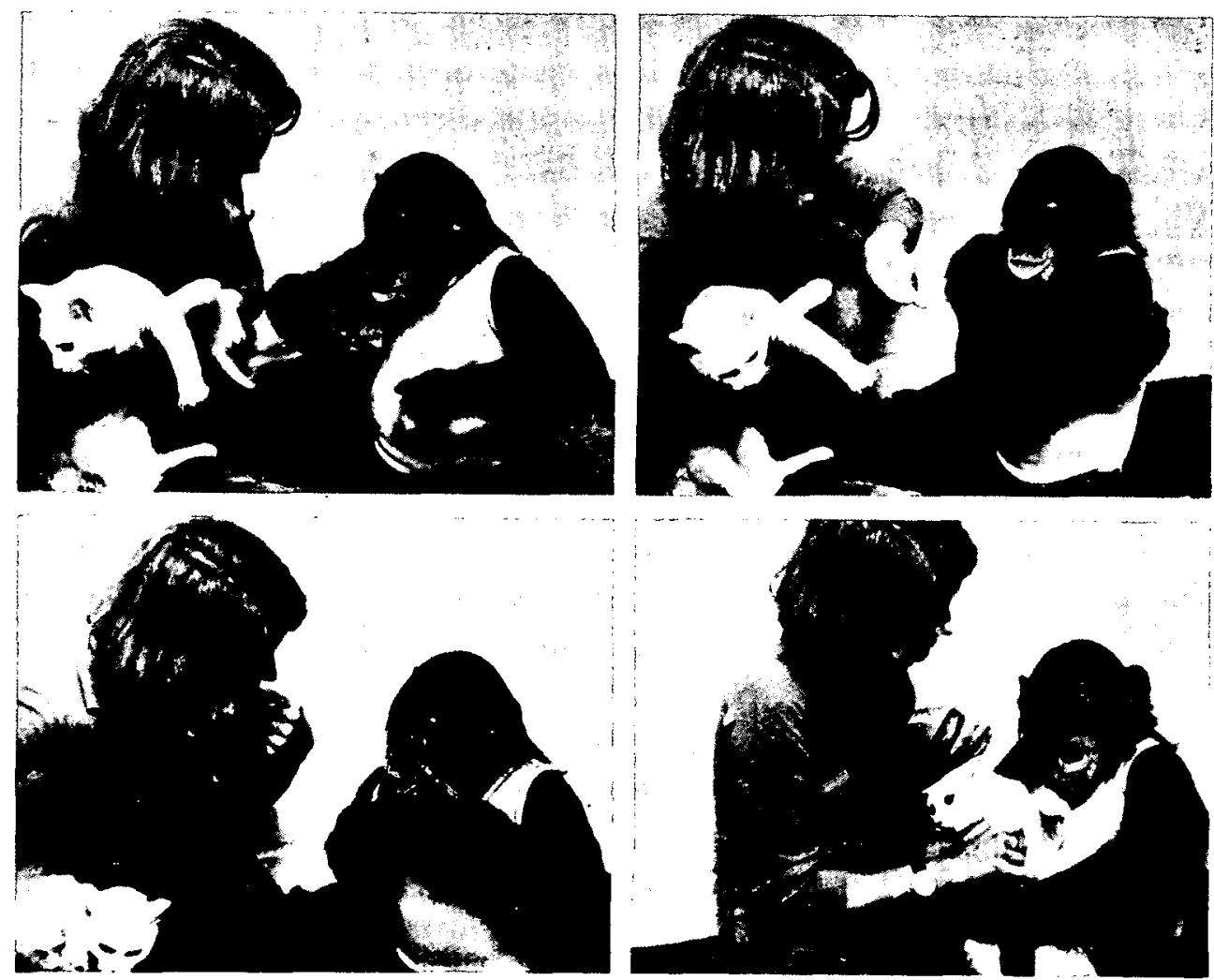

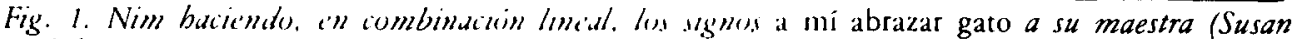
Quinby). (Fotografiada en la clase por H. S. Terrace.)

orden estereotipado derivado del uso del inglés y también podrán haberle dedicado, involuntariamente, una atención especial cuando emitía una combinación interesante; en cualquier caso, estas reacciones no intencionadas no serían distintas a las de los padres cuando el niño produce una locución interesante o ajustada al inglés correcto.

Las combinaciones lineales de Nim fueron sostenidas a tres tipos de análisis. En primer lugar, buscamos las regularidades en la distribución de las locuciones de dos signos de Nim: ¿ponía Nim determinados signos en la primera o en la segunda posición de las combinaciones? En segundo lugar, después de confirmar la existencia de regularidades en el léxico de las combinaciones de dos signos, indagamos en busca de regularidades semánticas en un corpus menor, formado por aquellas combinaciones de dos signos de las que se poseía una información contextual adecuada. Los resultados de estos análisis fueron equívocos. En tercer lugar, el análisis del adiálogo» en las transcripciones de la cinta video mostró que los signos de Nim eran ayudados a menudo por los signos anteriores de sus maestros.

Corpus y regularidades en la distribución

Desde los dieciocho a los treinta y cinco meses de edad, los maestros de Nim recogieron en sus informes 5.235 tipos entre las 19.203 muestras de combinaciones de dos a cinco o más signos. Las distintas secuencias de los mismo signos se consideraron tipos diferentes (por ejemplo, plátano comer o comer plátano). El númeto de tipos y muestras de cada longitud de combinación creció linealmente en todos los casos (Tabla 1) $(30,31)$.

La gran variedad de tipos de combinación y el no haberse exigido a Nim que combinase los sig. nos es suficiente para demostrar que las combinaciones de Nim no se debían a un aprendizaje mecánico. La aparición de más de 2.700 tipos de combinaciones de dos o tres signos sobrepasa la capacidad de cualquier estimación conocida de 


\section{Estudios}

Tabla 1. Número de muestras y tipos de combinación de dos, tres, cuatro y cinco o más signos.

\begin{tabular}{|c|c|c|}
\hline Longitud de la combinación & Muestras & Tipos \\
\hline Dos signos & 11,845 & 1,138 \\
\hline Tres signos. & 4,294 & 1,660 \\
\hline Cuatro signos & 1,587 & 1,159 \\
\hline Cinco o más signos . . . & 1,487 & 1,278 \\
\hline
\end{tabular}

la memoria de un chimpancé. Como se ha dicho antes, sin embargo, una gran variedad de combinaciones no es suficiente para demostrar que esas combinaciones son oraciones, es decir, que expresan una proposición semántica en una secuencia de signos gobernada por reglas. Mientras no existan pruebas adicionales, la explicación más sencilla es que la locuciones de Nim son combinaciones no estructuradas de sig. nos en que cada signo por separado se ajusta a la situación del momento.

La regularidad de las combinaciones de $\mathrm{Nim}$ hace pensar que se generaban mediante reglas, y era mas acusada en las combinaciones de dos signos. Como muestra la Tabla 2 , más $+X$ es más frecuente que $X+$ más, dar $+X$ más que $X+d a r$, y verbo + a mío Nim más que a mío $\mathrm{Nim}+$ verbo. En la Tabla 3 (32) se registra un ejemplo de la regularidad de las combinaciones de dos signos, las combinaciones de los verbos. transitivos con las referencias a sí mismo (a. mí o Nim). El número de muestras con el verbo en primera posición excede en mucho al de orden inverso. Igualmente, Nim combinaba los verbos transitivos lo mismo que con a mí que con $\operatorname{Nim}$ (33).

También era evidente que prefería utilizar $a$ mí o Nim en la segunda posición de las combinaciones de dos signos para pedir diversos objetos, comestibles o no (Tabla 2).

Tabla 2. Frecuencia de determinados signos en posición inicial o final de las combinaciones de dos signos.

\begin{tabular}{|c|c|c|c|}
\hline Combinación & & Tipos & Muestras \\
\hline $\begin{array}{l}\text { Más } \\
\mathrm{X}\end{array}$ & $\begin{array}{l}+\mathrm{X} \\
+m a ́ s\end{array}$ & $\begin{array}{l}47 \\
27\end{array}$ & $\begin{array}{l}974 \\
124\end{array}$ \\
\hline $\begin{array}{l}\text { Dame } \\
\mathrm{X}\end{array}$ & $\begin{array}{l}+\mathrm{X} \\
+ \text { dame }\end{array}$ & $\begin{array}{l}51 \\
24\end{array}$ & $\begin{array}{r}271 \\
77\end{array}$ \\
\hline Verbo transitivo & $\begin{aligned} & a m i ́ \\
+ & o \\
& N i m\end{aligned}$ & 25 & 788 \\
\hline $\begin{array}{l}A m i \\
\text { o } \\
N i m\end{array}$ & + Verbo transitivo & 19 & 158 \\
\hline Nombre (comida / bebida) & $\begin{aligned} & A m i \\
+ & 0 \\
& N i m\end{aligned}$ & 34 & 775 \\
\hline $\begin{array}{l}A m i \\
0 \\
N i m\end{array}$ & + nombre (com./beb.) & 26 & 261 \\
\hline Nombre (no de com./beb.) & $\begin{aligned} & A m i \\
+ & 0 \\
& N i m\end{aligned}$ & 35 & 181 \\
\hline $\begin{array}{l}\text { A mi } \\
\mathbf{o} \\
\mathrm{Nim}\end{array}$ & + nombre (no de com./beb.) & 26 & 99 \\
\hline
\end{tabular}


Tabla 3. Combinaciones de dos signos con a mí o. Nim y verbos transitivos [V (t)].

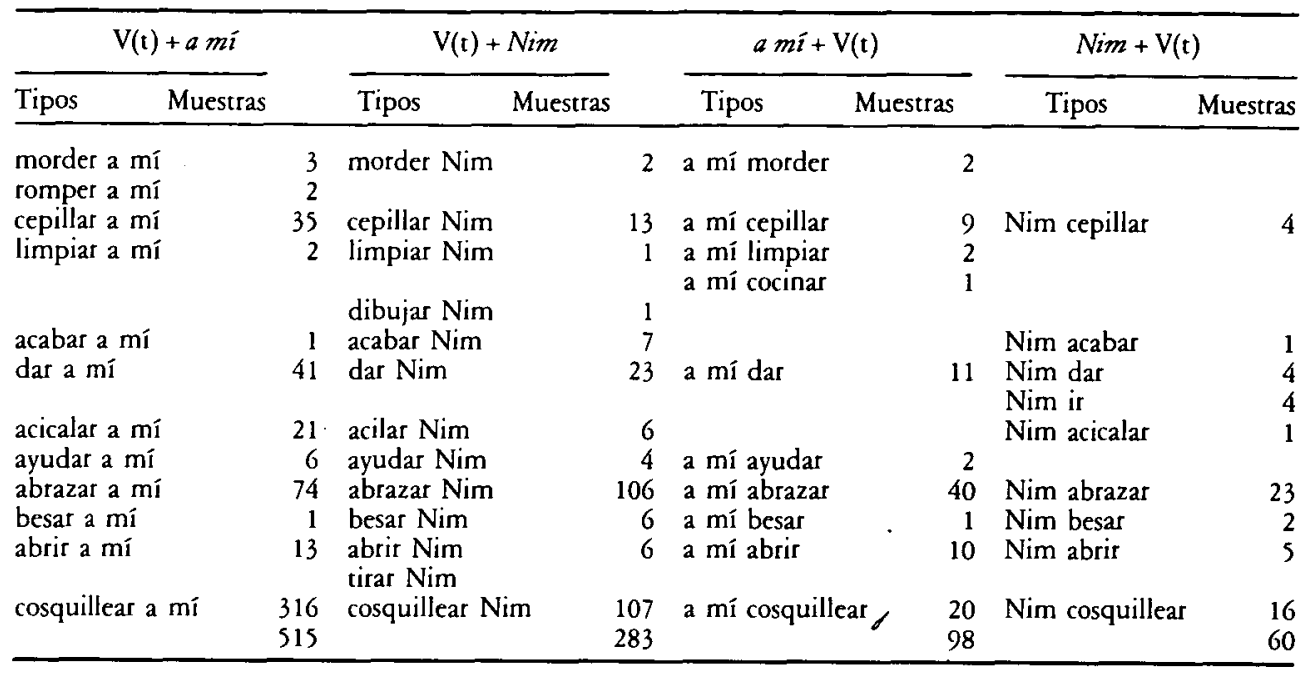

Total de tipos: 25

Total de muestras: 788
Total de tipos: 19

Total de muestras: 158
Las pautas de frecuencia diferente, com las presentadas en las tablas 2 y 3 no bastan para demostrar que exista una restrinción estructural en las secuencias de Nim. Este podrá tener un conjunto de hábitos independientes de primera y se: gunda posición que generarán las regularidades que observábamos en la distribución. La interpretación más sencilla de estas regularidades, sin necesidad de postular reglas sintácticas, sería que Nim utilizaba ciertas categorías en posición inicial o final, sin tener en cuenta el contexto en que aparecían. Si esto fuera así, debería ser posible predecir las frecuencias teóricas de las distintas construcciones, como verbo $+a$ mi o ver. bo + Nim, a partir de la frecuencia relativa en posición inicial o final de sus componentes.

La exactitud de estas predicciones se puso a prueba asignando cada uno de los dos signos de una secuencia a una categoría léxica y utilizando después las frecuencias relativas de esas categorías para predecir las probabilidades de cada tipo léxico de dos signos. El valor pronosticado de la probabilidad de una secuencia concreta se calculó multiplicando las probabilidades de los tipos léxicos relevantes en primera y segunda posición, respectivamente. Para predecir la probabilidad de a mí comer, por ejemplo, se multiplicó la probabilidad de a mí en primera posición (.121) por la de comer en segunda posición (.149), lo que suponía una frecuencia relativa de .016 .

La correlación entre 124 pares de probabilidades pronosticadas y observadas fue .0036 . Parece razonable concluir que, en general, las secuen- cias de dos signos de Nim no son generadas por hábitos independientes de posición. Además, no es posible predecir las frecuencias observadas de la posición relativa de los tipos léxicos de las combinaciones de tres signos a partir de la frecuencia relativa de sus componentes. La correlación entre los 66 pares de probabilidades pronosticadas y observadas fue sólo .05 .

Relación entre las combinaciones de dos, tres y cuatro signos de Nim

Cuando los niños aúmentan la longitud de sus locuciones elaboran éstas, inicialmente cortas, para proporcionar información suplementaria sobre algún tema $(20,22)$. Por ejemplo, en lugar de decir sentar silla, el niño podría decir sentar papá silla. En general, es posible considerar que las locuciones extensas están compuestas por elementos más cortos que habían sido dominados por separado. Las locuciones más largas no son, sin embargo, meras combinaciones de locu. ciones corras. Al producir locuciones de mayor longitud, el niño combina las palabras de las locuciones cortas en un sólo orden; elimina los elementos repetidos y trata las locuciones más cortas como unidades que se utilizan para desarrollar lo que previamente habrá sido expresado por una sola palabra.

El argumento aparente de las combinaciones de tres signos de Nim se solapaba considerablemente con el argumento aparente de sus combinaciones de dos signos (Tabla 4). Dieciocho de 
Tabla 4. Las veinticinco combinaciones más frecuente con dos y tres signos.

\begin{tabular}{|c|c|c|c|c|c|c|}
\hline \multicolumn{2}{|c|}{ Combinaciones de dos signos } & \multirow{2}{*}{$\frac{\text { Frecuencia }}{375}$} & \multicolumn{3}{|c|}{ Combinaciones de tres signos } & Frecuencia \\
\hline jugar & a mí & & jugar & a mí & Nim & 81 \\
\hline a mí & Nim & 328 & comer & a mí & Nim & 48 \\
\hline cosquillear & a mí & 316 & comer & Nim & comer & 46 \\
\hline comer & $\mathrm{Nim}$ & 302 & cosquillear & a mí & Nim & 44 \\
\hline más & comer & 287 & uva & comer & $\mathrm{Nim}$ & 37 \\
\hline a mí & comer & 237 & plátano & Nim & comer & 33 \\
\hline Nim & comer & 209 & Nim & a mí & comer & 27 \\
\hline acabar & abrazo & 187 & plátano & comer & $\mathrm{Nim}$ & 26 \\
\hline beber & $\mathrm{Nim}$ & 143 & comer & a mí & comer & 22 \\
\hline más & cosquillear & 136 & a mí & Nim & comer & 21 \\
\hline perdón & abrazo & 123 & abrazo & a mí & $\mathrm{Nim}$ & 20 \\
\hline cosquillear & Nim & 107 & yogur & $\mathrm{Nim}$ & comer & 20 \\
\hline abrazo & $\mathrm{Nim}$ & 106 & a mí & más & comer & 19 \\
\hline más & beber & 99 & más & comer & $\mathrm{Nim}$ & 19 \\
\hline comer & beber & 98 & acabar & abrazo & Nim & 18 \\
\hline plátano & a mí & 97 & plátano & a mí & comer & 17 \\
\hline $\mathrm{Nim}$ & a mí & 89 & Nim & comer & $\mathrm{Nim}$ & 17 \\
\hline dulce & Nim & 85 & cosquillear & a mí & cosquillear & 17 \\
\hline a mí & jugar & 81 & manzana & a mí & comer & 15 \\
\hline chicle & comer & 79 & comer & Nim & a mí & 15 \\
\hline té & beber & 77 & dar & a mí & comer & 15 \\
\hline uva & comer & 74 & nuez & Nim & nuez & 15 \\
\hline abrazo & a mí & 74 & bebida & a mí & Nim & 14 \\
\hline plátano & $\mathrm{Nim}$ & 73 & abrazo & a mí & abrazo & 14 \\
\hline en & pantalones & 70 & dulce & $\mathrm{Nim}$ & dulce & 14 \\
\hline
\end{tabular}

Tabla 5. Las combinaciones más frecuentes de cuatro signos.

Combinaciones de cuatro signos

Frecuencia

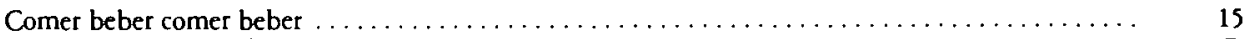

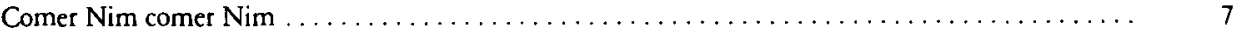

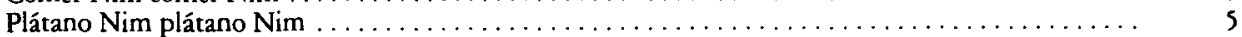

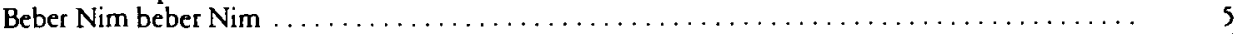

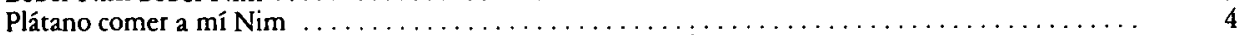

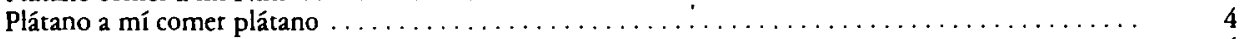

Plátano a mí Nim a mí . . . . . . . . . . . . . . . . . . . . . . . . . . . . . 4

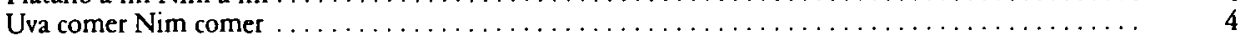

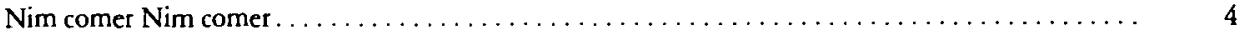

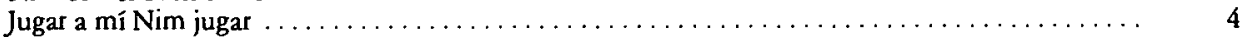

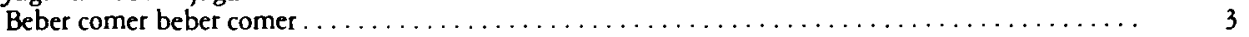

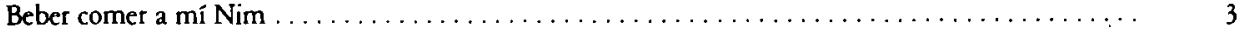

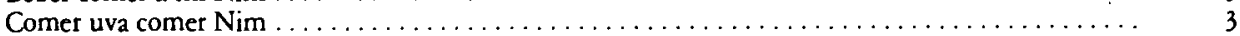

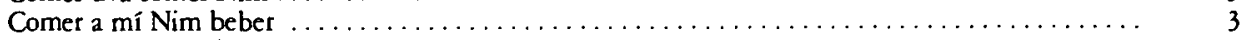

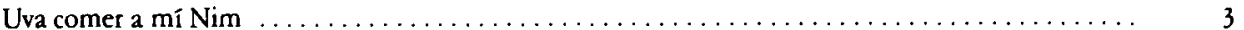

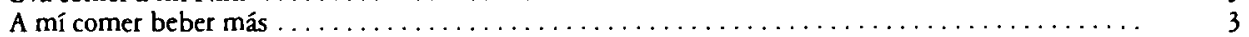

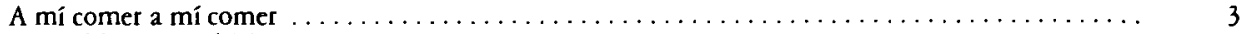

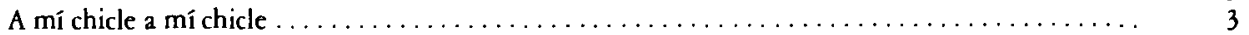

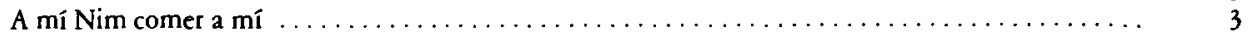

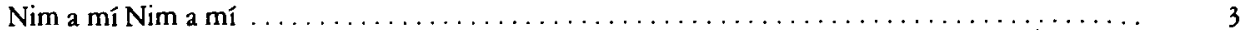

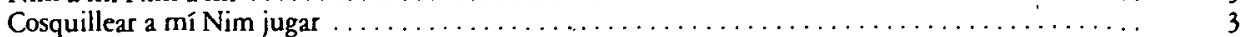


las veinticinco combinaciones más frecuentes de dos signos de Nim estaban presentes en las veinticinco combinaciones más frecuentes de tres sig. nos en el mismo orden, prácticamente, en que aparecían en las de dos signos. Además si se ignora el orden de los signos se observa que todos ilos signos que aparecen en las veinticinco combinaciones más frecuentes de dos signos, menos cinco (chicle, té, perdón, dentro, pantalones) aparecen en las veinticinco combinaciones más frecuentes de tres signos. No tenemos la información contextual necesaria para llevar a cabo un análisis semántico de las combinaciones de dos y tres signos de Nim, sin embargo, los informes de los maestros de Nim señalan que los signos individuales de sus combinaciones de adecuaban al contexto y que las combinaciones equivalentes de dos o tres signos aparecían en el mismo contexto.

Las combinaciones de tres signos (Tabla 4), aunque eran semejantes a las de dos signos en el léxico, no parecen ser elaboraciones informativas de las combinaciones de dos signos. Pueden considerarse las combinaciones más frecuentes de Nim de dos y tres signos: jugar a mí y jugar a mi Nim. Al combinarse Nim con jugar a mí para producir una combinación de tres signos, jugar a mi $\mathrm{Nim}$, se añade un nombre propio redundante a un pronombre personal. La repetición es otra característica de las combinaciones de tres signos, por ejemplo, comer Nim comer y nuez Nim nuez. Al producir una combinación de tres signos parece como si Nim estuviera añadiendo algo a lo que podría emitir en una combinación de dos signos, no tanto una nueva información sino más bien un énfasis suplementario. Las combinaciones mäs frecuentes de cuatro signos de Nim (Tabla 5) presentan una disposición similar. En las locuciones de los niños, por el contrario, la repetición de una palabra o de una secuencia de palabras, es un hecho extraño (34).

\section{Diferencias entre las locuciones} de Nim y las del niño

El hecho de que las locuciones extensas no fueran elaboraciones semánticas entre las primeras locuciones de varias palabras de Nim y las de un niño. Estas y otras diferencias indican que el uso general de las combinaciones por Nim presenta sólo una semejanza superficial con las primeras locuciones del niño (35-38).

\section{La longitud media \\ de las locuciones de Nim}

Al tiempo que aumenta la longitud media de las locuciones (LML) de un niño, aumenta tam- bién su complejidad progresivamente (20-32). En inglés, por ejemplo, las construcciones sujeto-verbo y verbo-objeto se funden en la construcción sujeto-verbo-objeto.

La Figura 2 presenta la LML (número medio de signos en cada locución) de Nim entre los veintiséis y cuarenta y cinco meses de edad (39). El hecho más sorprendente de estas curvas es la ausencia de crecimiento de la LML de Nim durante un período de diecinueve meses. La Figura 2 también muestra curvas comparables de la LML en niños que oyen ( $y$ hablan), y sordos (que hablan por signos) (40), incluido el menor crecimiento normal de la LML que hemos podido encontrar en un niño con habla. Todos los niños empiezan con una LML semejante a la de Nim a los treinta y seis meses, pero, a diferencia de Nim, aumentan sin excepción su LML.

Otra diferencia entre la LML de Nim y los niños tienen que ver con el valor de la LML y su límite superior. Según Brown a... el límite superior de la distribución (de la LML) guarda una relación bastante estrecha con la media... Con una $\mathrm{LML}=2.0$ el límite superior estaría, como mucho, entre $5 \pm 2$ s (41). Sin embargo, con una LML de $1.6 \mathrm{Nim}$ producía locuciones de hasta 16 signos (dar naranja a mí dar comer naranja a mí comer naranja dar a mi comer naranja dar a mí tu). Cuando analicemos el diálogo de signos de Nim y Washoe ( $v$. abajo), sugeriremos mecanismos que puedan aumentar la longitud de la locución de un antropoide sin que presuponga un incremento de la competencia semántica o sintáctica.

\section{Relaciones semánticas expresadas en las combinaciones de dos signos de Nim}

Las distribuciones semánticas, a diferencia de las léxicas que hemos discutido arriba, no pueden construirse directamente a partir de un corpus. Para derivar una distribución semántica, los observadores tienen que juzgar qué significa cada combinación. Los procedimientos para realizar estos juicios, introducidos por Bloom $(19,20)$ y Schlesinger $(42)$, son conocidos como método de la einterpretación amplias (21-23, 42). Un observador relaciona el contexto inmediato de la locución con su contenido. Las pruebas que sustentan los juicios semánticos incluyen las observaciones siguientes. El niño elige generalmente el mismo orden de palabras que utilizaría el adulto en la expresión corriente de la misma idea; cuando aumenta la LML del niño, las relaciones semánticas identificadas por medio de una interpretación amplia se desarrollan de un modo ordenado $(20,22,43)$; las 


\section{Estudios}
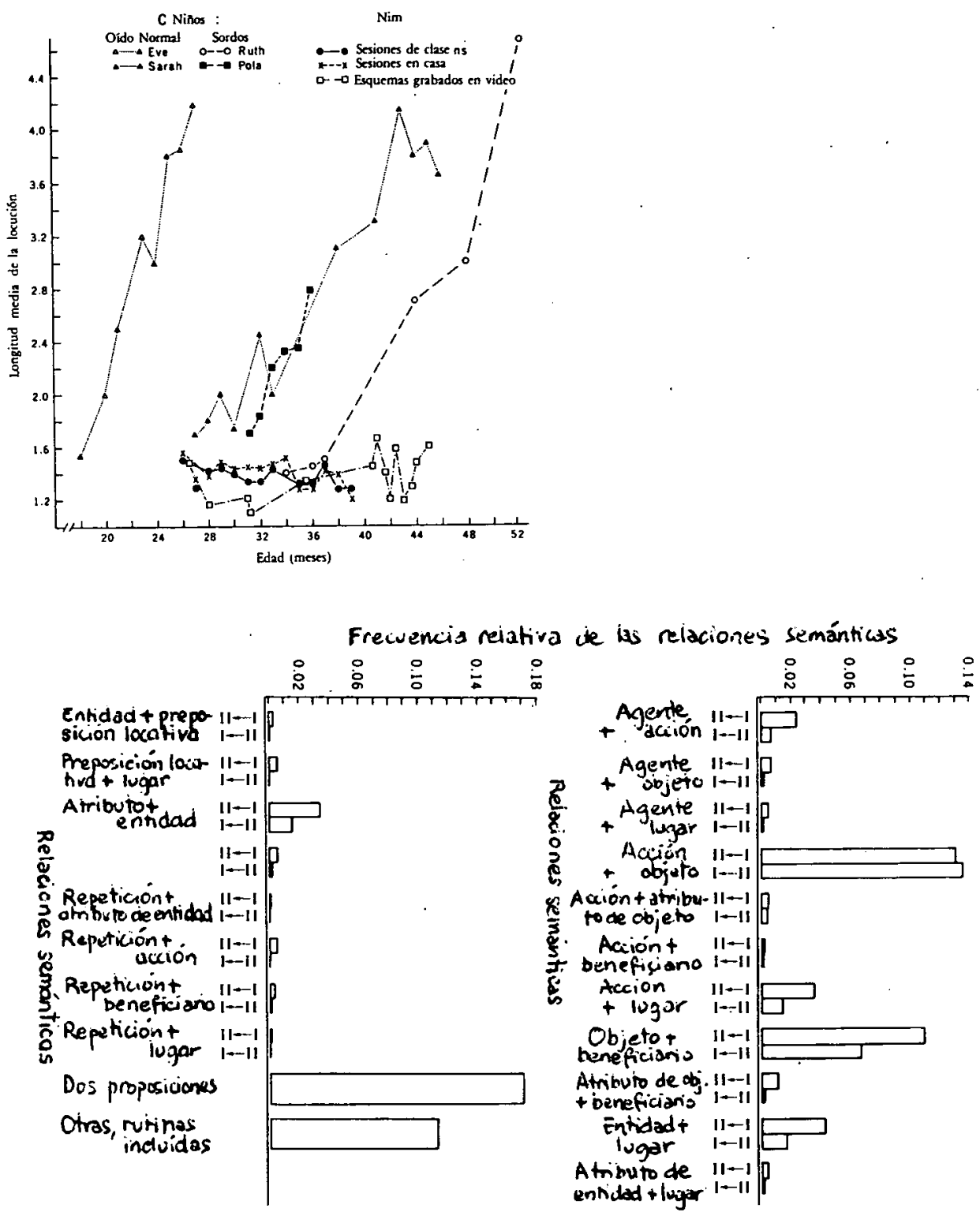

Fig. 2 (izquierda). Longitud media de las locuciones de signos de Nim y de tres niños sordos y de las locuciones habladas de dos niños con oído normal. La curva de la LML de Nim entre enero de 1976 y febrero de 1977 (edad, veintiséis a treinta y nueve meses) se basa en los datos obtenidos de los informes de los maestros. La curva de la LML de Nim entre febrero de 1976 y agosto de 1977 (edad, vein. tisiete a cuarenta y cinco meses) se basa en los datos de las transcripciones del video -véase (39) en relación al cálculo de la LML en las locuciones de signos-. Fig. 3 (derecha). Frecuencias relativas de las distintas relaciones semánticas. Las barras sobre I y II muestran las frecuencias relativas de las combinaciones de dos signos que expresan una relación en el orden especificado bajo la barra, por ejemplo, un agente seguido de una acción. Las barras sobre II - I muestran las frecuencias relativas de las combinaciones de dos signos que expresan la misma relaciön en el orden inverso, por ejemplo, la acción seguida de un agente. 
relaciones expresadas en las combinaciones de dos palabras son las primeras que aparecen en las de tres y cuatro palabras; muchas locuciones extensas parecen estar formadas por relaciones semánticas expresadas en locuciones más cortas $(20,22)$.

Los estudios sobre la habilidad de los antropoides para expresar relaciones semánticas tienen que superar todavía la fase de interpretación no validada. Los Gardner (44) y Patterson (11) concluían que una parte sustancial de las combinaciones de dos signos de Washoe y Koko podrían interpretarse según categorías similares a las utilizadas para describir las locuciones de dos palabras de los niños ( 78 y 95 por 100 , respectivamente). No existen datos asequibles sobre la fiabilidad de las interpretaciones de los Gardner y Patterson.

A menudo se cita un ejemplo (agua ave) de la habilidad de Washoe para producir nuevos significados mediante combinaciones nuevas de los signos de sus locuciones. Fonts (45) especifica que Washoe emitió los signos agua ave en presencia de un cisne cuando se le pregunto ¿qué aquello? La respuesta de Washoe parece llena de sentido y creativa al yuxtaponer dos signos apropiados de forma compatible con el orden de palabras en inglés. Sin embargo, no hay ninguna base para concluir que Washoe estaba caracterizando al cisne como sun ave que vive en el agua». Washoe tenía una amplia experiencia en preguntas de ¿qué aquello? ante la presencia de aves u objetos acuáticos. En este caso, Washoe podía haber contestado sencillamente a la pregunta de ¿qué aquello? identificando correctamente un cuerpo acuático y un ave, en ese orden. Antes de concluir que Washoe relacionaba el signo agua con el signo ave, debe conocerse si colocaba con regularidad un adjetivo (agua) delante, o detrás, de un nombre (ave). Todo esto no puede decidirse a partir de una anécdota aislada, por muy sorprendente que sea para un observador de lengua inglesa.

Analizamos por el método de la interpretación amplia 1.262 combinaciones de dos signos de Nim, emitidas entre las edades de veinticinco a treinta y un meses (40), sin prejuzgar si realmente Nim expresaba relaciones semánticas en sus combinaciones. Los resultados de nuestro análisis semăntico se muestran en la Figura 3. Veinte categorías de relaciones semánticas explican 895 ( 85 por 100 ) de las 957 combinaciones interpretables de dos signos. Brown (47) encontró once relaciones semánticas que daban cuenta de aproximadamente el 75 por 100 de todas las combinaciones de los niños que estudió. Los Gardner y Patterson (48) utilizaron categorías semejantes de relaciones semánticas.
La Figura 3 muestra diversos casos de preferencias significativas en la posición: los signos que expresan un papel semántico determinado aparecen en posición inicial o final. El agente, el atributo y la repetición (más) se expresaban con mayor frecuencia en primera posición, mientras que el lugar y los paneles de beneficio se expresaban más frecuentemente mediante signos de segunda posición (49).

A primera vista, parece que coinciden los resultados de nuestro análisis semántico con las observaciones de los Gardner y Patterson. Pero incluso aunque nuestros juicios fueran fiables diversos rasgos de nuestros resultados hacen pensar que nuestros análisis, y los de otros, pueden exagerar la competencia semántica de Nim. Un problema reside en la naturaleza subjetiva de las interpretaciones semánticas. Este problema sólo puede resolverse en la medida que existan pruebas que corroboren la realidad psicológica de nuestras interpretaciones. Ni nuestros análisis semánticos de las combinaciones de dos signos de un antropoide ni los de ningún otro estudio han proporcionado tales pruebas. En algunos casos, las locuciones de nuestros registros eran intrínsecamente equívocas. Por consiguiente, se utilizaron reglas algo arbitrarias para interpretar estas locuciones. Considérense, por ejemplo, las combinaciones de Nim y a mí con un nombre de objeto (por ejemplo, Nim plätano). Ocurrían cuando el maestro mostraba un objeto que estaba a punto de dar a Nim que, a su vez, lo ingería. No tenemos una base firme para distinguir entre las interpretaciones semánticas siguientes de las combinaciones de $\mathrm{Nim}$ o a mí y un nombre de objeto: agente-objeto, beneficiario-objeto y poseedor-objeto poseído.

El número de unidades léxicas utilizadas para expresar papeles semánticos concretos, muy exiguo, plantea un problema igualmente difícil. Sólo cuando un papel semántico está representado por una gran variedad de signos es razonable atribuir las preferencias en la posición a reglas semánticas y no a hábitos léxicos de posición. Por ejemplo, el papel de repetición se indicaba exclusivamente por más. Si se piensa en las combinaciones que relacionan un agente y un objeto o un objeto y un beneficiario, podría esperarse que los agentes y beneficiarios cubrieran un amplio rango, por ejemplo: Nim, a $m i, t u, y$ nombres de otros seres animados. Sin embargo, el 99 por $100(\mathrm{~N}=297)$ de los beneficiarios en las locuciones clasificadas como combinaciones objeto-beneficiario fueron Nim y a mí, y en el 76 por $100(\mathrm{~N}=35)$ de las combinaciones agente-objeto, el agente era tú. Es dificil decidir, a partir de estos ejemplos y de otros, si las regula. ridades en la posición de las construcciones agente-objeto y objeto-beneficiario (Figura 3) 
expresan relaciones semánticas o hábitos idiosincrásicos de posición léxica. Estos efectos aislados también podrían esperarse si se considera la variación al azar.

\section{Análisis del diálogo}

El análisis de las transcripciones video proporcionó otra contribución al estudio semántico de las combinaciones de $\mathrm{Nim}$; las locuciones eran iniciadas a menudo por los signos de sus maestros y frecuentemente eran imitaciones, completas o parciales, de las locuciones precedentes de éstos. Puesto que estas imitaciones se incluían en el corpus, es posible que las relaciones semánticas y las preferencias de posición que observamos fuera, hasta cierto punto, un reflejo de los hábitos de producción de signos de los maestros. Las construcciones imitadas no pueden considerarse semejantes a las de un niño, no imitativas.

Existe un interés creciente en conocer cómo los padres hablan a sus hijos (50) y de qué manera los niños ajustan su lenguaje a los aspectos del contexto verbal anterior (51). Fillmore (52) ha comparado las conversaciones adultas a un juego en que los dos participantes se turnan en la conducción de un tema. Los niños aprenden con bastante rapidez que la conversación es un juego de turnos (53). Sin embargo, nuestro análisis del diálogo reveló una relación fundamen. talmente distinta entre las locuciones de Nim y las de su maestro.

El corpus que analizamos se obtuvo de las transcripciones de tres horas y media de cinta video de nueve sesiones grabadas entre los veintiséis y cuarenta y cuatro meses de edad (54). En la Fig. 4 se representa la comparación del diálogo de Nim y sus maestros con el diálogo de los niños y los adultos, según Bloom et al. (51). Son locuciones adyacentes las que siguen a una locución adulta sin una pausa definitiva (51). A los veintiún meses de edad $(\mathrm{LML}=1.3)$, que son el período de desarrollo más apropiado para la comparación con $\mathrm{Nim}$, la proporción media de las locuciones adyacentes del niño es el 69.2 por 100 (rango, 53 a 78 por 100). Un porcentaje algo superior de las locuciones de Nim (87 por 100) se clasificaron como adyacentes (rango, 58.7 a 90,9 por 100).

Las locuciones adyacentes pueden dividirse en cuatro categorías:

I. Son imitaciones las locuciones que contienen todos los elementos léxicos de las locuciones adultas y ninguno más.

II. Son reducciones las que contienen alguno de los elementos léxicos de la locución del adulto y ninguno nuevo.
III. Las expansiones contienen algunos de los elementos léxicos del adulto junto con otros nuevos.

IV. Locuciones nuevas son las que no contienen ninguno de lo elementos léxicos de la locución adulta.

En los niños estudiados por Bloom et al. (52). las imitaciones y las reducciones daban cuenta del 18 por 100 (Fig. 4) del total de locuciones del niño en el estadio $1(\mathrm{LML}=1.36)$. Este 18 por 100 disminuía al aumentar la LML, constituyendo sólo el 2 por 100 de las locuciones de los niños en el estadio 5 (LML=3.91). Por el contrario, el 39,1 por 100 de las locuciones adyacentes de $\mathrm{Nim}(\mathrm{N}=509)$ eran imitaciones o reducciones (rango, 19,5 a 57,1 por 100).

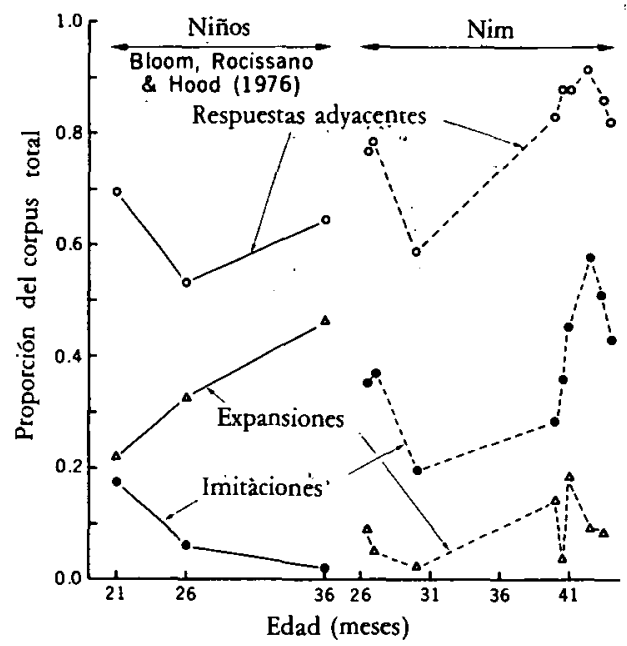

Fig. 4. Proporción de las locuciones emitidas. por los niños (gráfica a la izquierda) y por Nim (gráfica a la derecha), que son adyacentes, imitaciones o expansiones de una locución anterior de un adulto).

En el estadio 1, el 21,2 por 100 de las locuciones del niño son expansiones de la locución anterior del adulto (rango, 10 a 28 por 100). Sólo un promedio de 7,3 por 100 de las locuciones de Nim eran expansiones de la locución anterior de su maestro (rango, 1 a 15 por 100). Según crece el niño aumenta la proporción de expansiones entre las locuciones. Bloom et. al. (51) notaron que muchas locuciones del niño son expansiones sistemáticas de las relaciones verbales contenidas en la locución anterior del adulto. Esta pauta no aparecía en las expansiones de Nim. En realidad, un análisis preliminar de las expansiones de Nim indicaba que, aparte de los signos del maestro, sus locuciones contenían sólo un pequeño número de signos adicionales, como 
a $m \bar{i}$, Nim, tú, abrazar y comer. Dado que estos signos no están relacionados específicamente con contextos particulares, no añaden información nueva a la locución del maestro.

Por definicion, las locuciones adyacentes pueden incluir interrupciones de las locuciones de un adulto o un maestro. Tales interrupciones se apartan de la verdadera conversación, ya que dan lugar a un diálogo simultáneo, en vez de sucesivo. En el 71 por 100 de las locuciones que examinamos (425 de las 585), Nim realizaba dos signos al mismo tiempo que el maestro. De estas locuciones solapadas el 70 por 100 ocurrieron cuando Nim comenzaba una locución mientras su maestro hablaba por signos. Cuando el maestro internumpía una de las locuciones de Nim, era generalmente porque Nim había interrumpido a su vez al maestro y éste defendía, de hecho, su derecho a mantener el turno de palabra. Las interrupciones de Nim no proporcionan indicios para suponer que sean respuestas a los intentos del maestro de quitarle el turno de palabra. Hay pocos datos asequibles sobre la frecuencia relativa o la duración de las locuciones simultáneas que aparecen en los diálogos entre niño y adulto, lo mismo en el lenguaje de signos que en el hablado. En el estudio más pertinente que pudimos localizar, McIntyre esecifica que las transcripciones del video de un niño sordo de trece meses que hablaba por signos a su madre no mostraron virtualmente ninguna interrupción de las locuciones de la madre ( 54 a). Bloom (55) y Bellugi (50) han observado que las interrupciones no existen, de hecho, en sus cintas video del aprendizaje vocal y de lenguaje de signos en los niños ( $56 a$ ).

Ninguno de los maestros de Nim, ni de los muchos observadores expertos en lenguaje de signos, se daban cuenta del grado en que la iniciación y los contenidos de los signos de Nim dependían de los signos que emitía el maestro ni en qué medida Nim imitaba o interrumpía a sus maestros. Esta información únicamente puede obtenerse de las películas o cintas video. El contraste entre las conclusiones que podrían extraerse de nuestros análisis de las distribuciones y las que se derivan de nuestros análisis de los diálogos proporciona una importante lección metodológica. En ausencia de un registro permanente de los signos del antropoide y del contexto en que aparecen, ni siquiera un corpus, reunido objetivamente, de locuciones de un antropoide proporciona una base suficiente para extraer conclusiones sobre las regularidades gramaticales de estas locuciones.

En las fotografías como las de la Fig. 1 (serie de fotografías tomadas por una cámara con motor) se notan ejemplos inesperados, pero instructivos, de la influencia de los signos del maestro en los signos de Nim. El examen de la Fig. 1, inducido por los resultados de nuestro análisis del diálogo, revela que la maestra de Nim realizaba

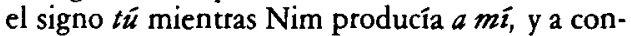
tinuación el signo ¿quién? mientras Nim emitía gato. No podemos especificar cuándo comenzó la maestra sus signos, porque esas cuatro fotografías son las únicas que tenemos de ese diálogo. No está claro, por ejemplo, si la maestra producía el signo tú simultánea o inmediatamente antes que el $a m i$ de Nim. Sin embargo, es improbable que la maestra realizara el signo ¿quién? después de que Nim hubiera dicho gato.

\section{Comparación del diálogo \\ de Nim con el de otros antropoides entrenados en el lenguaje de signos}

Dos valiosas fuentes de información que sugieren que el diálogo de Nim con sus maestros no se debía exclusivamente a las condiciones de nuestro proyecto son una película producida por Nova para la televisión, titulada «Los primeros signos de Washoe» (The first Signs of Washoe, 57) y una película producida por los Gardner, -La enseñanza del lenguaje de signos a una chimpancé: Washoe (Teaching Sign Language to the Chimpanzee: Washoe, 58).

Tabla 6. Diálogo entre Washoe (W) y B. Gardner (B. g.). Véase la Fig. 5. Es la transcripción de una cinta mostrada en la televisión.

\begin{tabular}{|c|c|c|c|}
\hline Tiempo & Cuadro & & \\
\hline $\begin{array}{r}00.00 \\
1.46 \\
1.96 \\
2.25 \\
4.50 \\
4.84\end{array}$ & $\begin{array}{r}7 \\
8 \\
9 \\
10 \\
11 \\
12\end{array}$ & $\begin{array}{r}\text { B. G.:/¿Qué } \\
\text { bora } \\
\text { abora?/ }\end{array}$ & $\begin{array}{l}\text { W: / hora } \\
\text { comer/ } \\
\text { /hora } \\
\text { comer/ }\end{array}$ \\
\hline & & . & -.....-empalme-............ \\
\hline
\end{tabular}




\section{Estudios}

Considérese la escena de «Los primeros signos de Washoe», que aparece en la Tabla 6 y en la parte izquierda de la Fig. 5 (59). En esta conversación, las locuciones de Washoe interrumpían o seguían a las locuciones de B. Gardner. También ocurre que el signo bora lo emitía B. Gardner justo antes de la locución de Washoe hora comer (60).
«La enseñanza del lenguaje de signos a un chimpancé: Washoes presenta una versión más amplia de la misma conversación. Como puede verse en la Tabla 7 y en la Figura 5 , los dos signos de Washoe (bora) y (comer) habían sido emitidos por B. Gardner justo antes de que Washoe los realizara. La locución hora comer no puede considerarse espontánea por dos razones.

Tabla 7. Diálogo entre Washoe (W) y B. Gardner (B.G.).

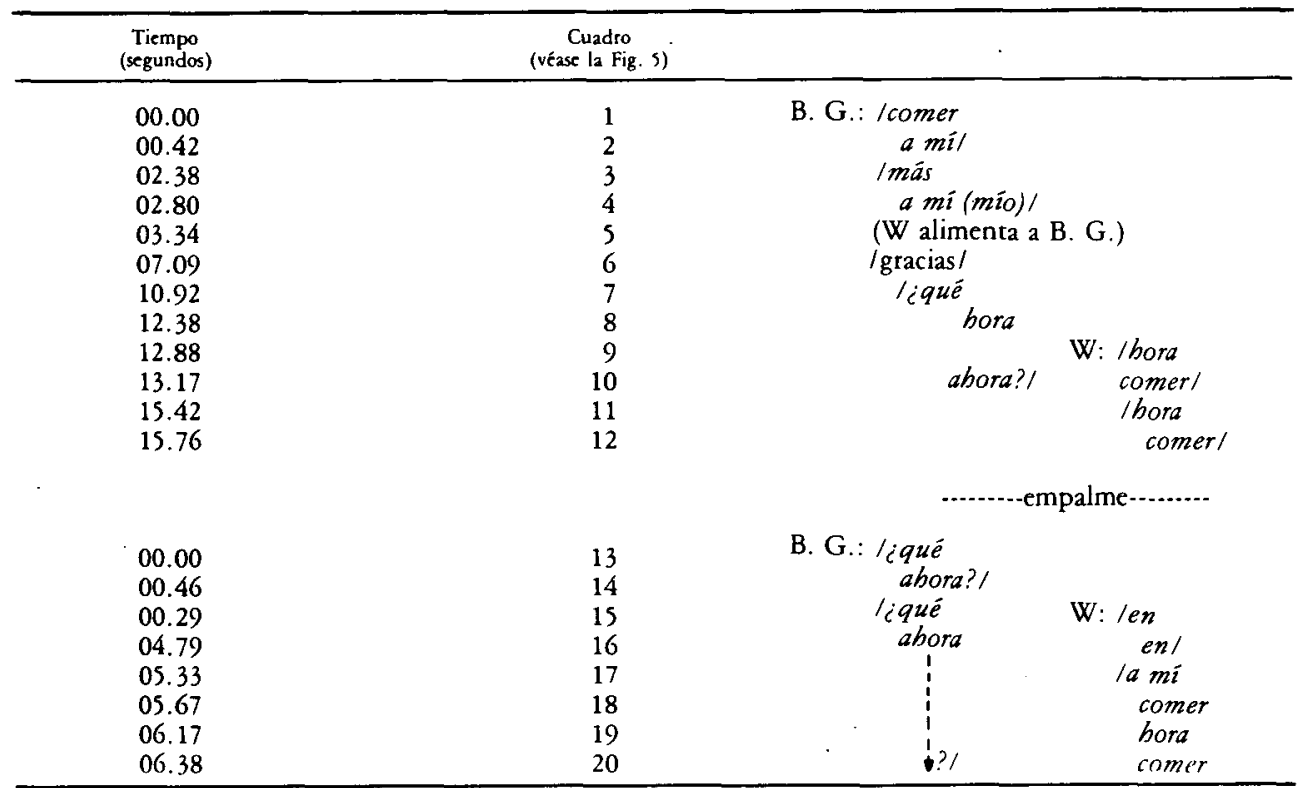
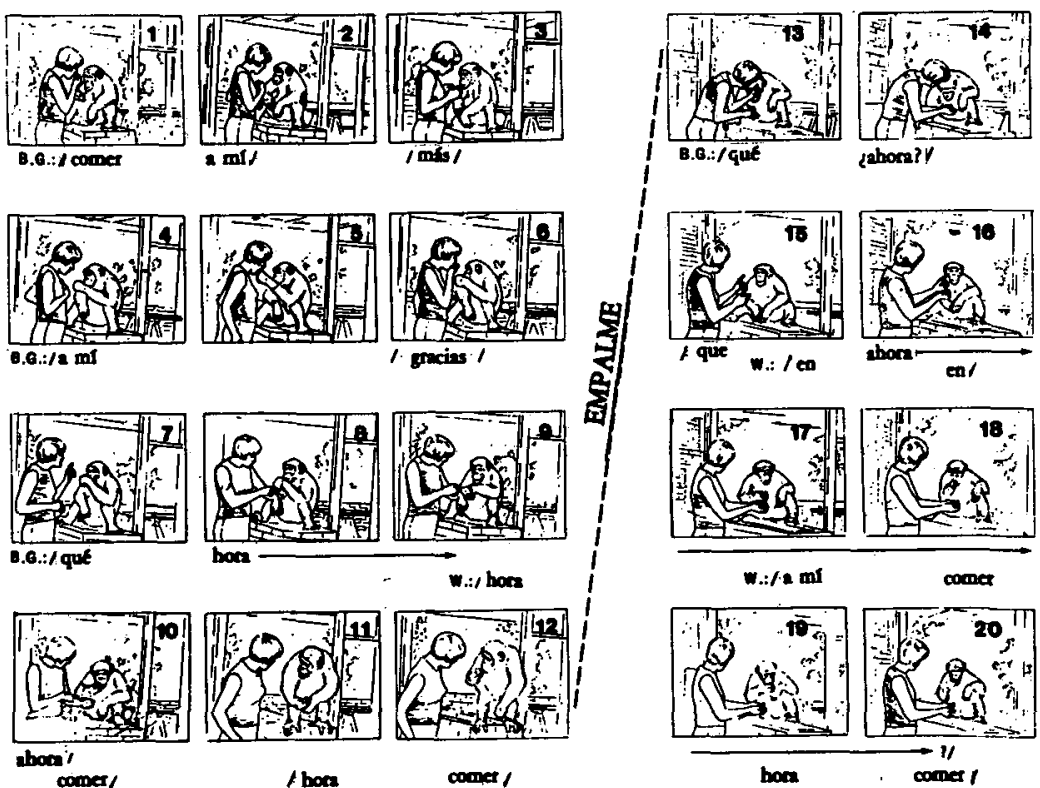

Fig. 5. Esquemas (dibujus de una película) de los signos de Washoe con B. Gardner. Véase (59). 
Era una respuesta a una petición de signos de B. Gardner y contenía signos emitidos anteriormente por ésta. La importancia de los registros completo del diálogo entre el chimpancé y su maestro se percibe también en el segmento que sigue al empalme en la película. Considérese aisladamente la combinación de Washoe $a m i$ comer hora. Si no conociéramos las locuciones anteriores del maestro sería muy fácil interpretar la locución de Washoe como una descripción de la conducta futura, con cierto conocimiento del tiempo. Nuestra transcripción del diálogo entre B. Gardner y Washoe muestra, del mismo modo, que tres de las cuatro locuciones de Washoe intertumpian locuciones de B. Gardner.
Otro ejemplo instructivo de la influencia del maestro en la producción de signos de Washoe lo constituye la locución glosada como niña en mi bebida (Fig. 6 y Tabla 8), combinación de cuatro signos descrita en las dos películas como utilización creativa del lenguaje de signos por Washoe. En esta secuencia (continua), el orden de los signos de Washoe refleja el orden en que la maestra (Susan Nichols) realizaba los signos a Washoe para que ésta emitiera signos acerca de una muñeca en una copa. La secuencia de los signos de la maestra (apuntar a la muñeca y después a la copa) sigue el orden exigido por una frase prepositiva en inglés. Sólo los dos últimos signos. mi y bebida. aparecían sin ayuda previa

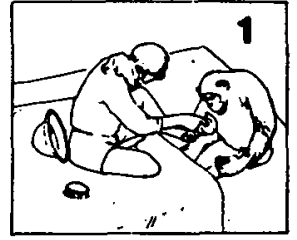

S.N::/ aquello

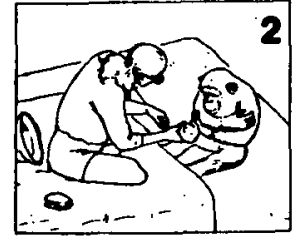

W.:/ niña

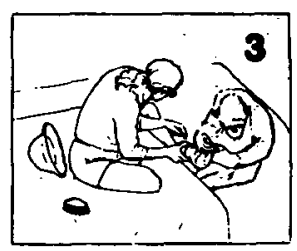

/ aquello ien

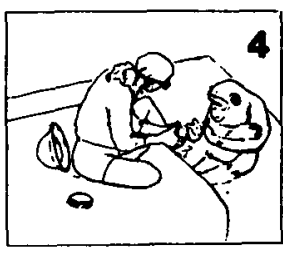

w:/niña

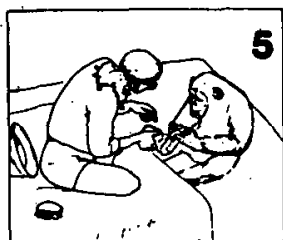

S.N.:/ aquello en

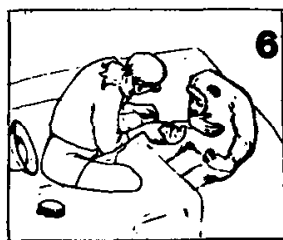

mi

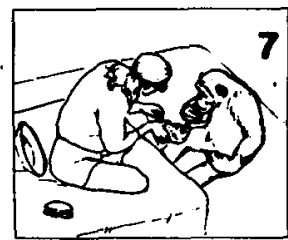

bebida!

Fig. 6: Esquemas de los signos de Washoe (dibujados de una película) con S. Nichols. Véase (59).

Tabla. 8. Diálogo entre Washoe (W) y S. Nichols (S.N.).

\begin{tabular}{|c|c|c|c|}
\hline Tiempo & $\begin{array}{c}\text { Cuadro } \\
\text { (véase } \\
\text { Fig. 6) }\end{array}$ & & \\
\hline 00.00 & 1 & S.N. laquello/ (señala la copa) & \\
\hline 00.29 & 2 & & $\mathrm{~W}: /$ niñal \\
\hline & & (acerca la copa y la muñeca & \\
\hline & & a W.; S.N. permite que W toque & \\
\hline & & lentamente). & \\
\hline \multirow[t]{5}{*}{05.37} & 3 & S.N.:/aquello/ (señala la copa) & \\
\hline & & & $\mathrm{W}:$ /en/ \\
\hline & & & $\begin{array}{l}\text { (aparta la vista de } \\
\text { S.N.) }\end{array}$ \\
\hline & & S.N.: (acerca la copa & \\
\hline & & y la muñeca a W) & $\begin{array}{l}\text { W: (mira desde atrás la copa } \\
\text { y la muñeca) }\end{array}$ \\
\hline \multirow[t]{2}{*}{08.17} & 4 & & $\mathrm{~W}: /$ niñal \\
\hline & & S.N.:(acerca la copa a W) & \\
\hline 10.58 & 5 & & W:/en! \\
\hline 11.46 & 6 & S.N.:/aquéllo/(señala la copa) & $\mathrm{W}: / m i$ \\
\hline 11.42 & 7 & & bebidal \\
\hline
\end{tabular}




\section{Estudios}

por parte ac la maestra. El signo glosado en la película como mi es formalmente idéntico al signo a mí de la Figura 5, Cuadro 17. Los dos signos cumplen los requisitos exigidos por los Gardner (1, pág. 264) para el signo $m i$, en su descripción de los signos de Washoe. Solamente por estas razones la secuencia real de signos de Washoe, niña en niña en mi bebida, no puede considerarse una producción espontánea.

Justo en la escena anterior de la película, Susan realizaba un ejercicio con los signos niña en zapato y manzana en sombrero, mientras Washoe intentaba quitar a la maestra los objetos deseados, lo que hace pensar que el signo mi de Washoe, en niña en niña en mi bebida, pretendía indicar a la maestra que quería la muñeca. Dado este tipo de ejercicio y dado que la maestra señalaba los objetos que debían nombrarse en la secuencia apropiada, es gratuito considerar la locución de la Fig. 6 una yuxtaposición creativa de signos con el significado «una muñeca en la copa de Washoes.

Como ejemplo final del diálogo de Washoe con sus maestros, puede considerarse la conversaión de la Tabla 9 sobre la inteligencia de Washoe; esta secuencią también parece ser un ejercicio. Sin embargo, la cuestión importante que se plantea es si Washoe comprendía real. mente los significados de estúpido (y listo). El uso que hacia de estúpido era una imitación clara de su maestra. El intercambio entre Washoe y la maestra (Susan Nichols) terminó en el momento en que la maestra introdujo a Washoe a realizar los signos estúpido y Washoe. Las circunstancias en que ocurría esta secuencia de signos dan lugar a interrogantes sobre el análisis semántico de los Gardner de las combinaciones como Naiomi bueno (44). Esta locución se presentó como ejemplo de atribucción, interpretación adecuada sólo si están ausentes las clases de in- ducción y recompensa mostradas en las películas de los signos de Washoe.

La película de duración más larga ${ }^{(1)}$ mostraba 155 locuciones de Washoe, de las que 120 tenían sólo un signo. Aparecían, principalmente, en las sesiones de prueba de vocabulario. Cada secuencia de varios signos ( 24 de dos signos, 6 de tres y 5 de cuatro) habían ido precedida por locución similar o una ayuda del maestro. Por tanto, las locuciones de Washoe eran contiguas o imitaciones de las locuciones de su mestro. El filme de Nova, que también presenta a Ally (hermano de Nim) y a Koko, revela una tendencia similar, por parte del maestro, a emitir signos antes que el antropoide lo hiciera. El 92 por 100 de los signos de Ally y la totalidad de los de Koko habían sido emitidos por el maestro justo antes que Ally y Koko los realizaran.

Obviamente, los datos proporcionados por unas pocas películas ofrecen una panorámica mucho más limitada que los datos que hemos obtenido de nuestras nueve cintas video. Parece razonable, sin embargo, asumir que los segmentos mostrados en el filme, los únicos asequibles sobre el lenguaje de signos de los antropoides, presentan los mejores ejemplos de signos de Washoe, Ally y Koko. Estas películas muestran, incluso con más claridad que nuestras transcripciones, que el maestro tenía consistentemente a iniciar los signos y que los signos del antropoide reflejaban los signos inmediatamente anteriores del maestro.

\section{Otras pruebas de la competencia gramatical de los antropoides}

Al valorar la afirmación de que los antropoides pueden producir y comprender oraciones

Tabla 9. Diálogo entre Washoe (W) y S. Nichols (S.N.).

\begin{tabular}{|c|c|c|}
\hline $\begin{array}{c}\text { Tiempo } \\
\text { (segundos) }\end{array}$ & Diälogo & \\
\hline $\begin{array}{l}00.00 \\
00.42 \\
05.30 \\
05.58 \\
06.42 \\
06.72 \\
07.04 \\
07.36\end{array}$ & $\begin{array}{l}\text { S.N.:/¿quiên estüpido?/ } \\
\text { S.N.:/¿quiên estüpido?/ } \\
\text { S.N.:/¿quiên/ } \\
\text { S.N.:/Wasboe/ } \\
\text { S.N.:/(hace cosquillas } \\
\text { Washoe)/ }\end{array}$ & $\begin{array}{l}\text { W:/Susan, Susan/ } \\
\text { W:/estúpido/ } \\
\text { W:/Washoe/ }\end{array}$ \\
\hline
\end{tabular}

(1) La enseñanza del lenguaje de signos a una chimpancé: Washoe». 
es importante tener en cuenta que se carece de una prueba decisiva que indique si una secuencia concreta de palabras constituye una oración, o si una ejecución particular puede calificarse de comprensión de oraciones, regida gramaticalmente. Se ha observado con frecuencia que las primeras secuencias de palabras emitidas por un niño no deben considerarse necesariamente oraciones $(19,24)$. Si, realmente, la única prueba de que el niño puede generar y comprender oraciones fueran sus primeras locuciones y las respuestas a las locuciones de sus padres, habría poca base para concluir que la producción y la comprensión de palabras están regidas por una gramática.

Una interpretación amplia de las primeras locuciones de un niño pequeño asume que hay restricciones impuestas por las reglas estructurales $(20,22)$. Es difícil, sin embargo, excluir interpretaciones más sencillas de estas locuciones. La expresión aislada de una secuencia de palabras podía ser una concatenación al azar sin ninguna relación estructural entre las palabras (22), o una rutina que el niño aprende mecánicamente al imitar el lenguaje de sus padres (24). Sin embargo, según crece el niño aumentan gradualmente la variedad y la compejidad de sus locuciones $(21,61)$. Tiene un interés especial la observación de que los niños atraviesan fases en las que producen sistemáticamente clases incorrectas de locuciones. Durante estas fases el niño «ensaya aparentemente diferentes conjuntos de reglas antes de conseguir la gramática correcta. Los niños también son capaces de distinguir entre oraciones gramaticalmente correctas $e$ incorrectas (62). Por consiguiente, las explicaciones de sus locuciones que no se basen en algún tipo de gramática se vuelven demasiado difíciles de defender.

\section{Producción de secuencias}

Antes de afirmar que una secuencia de palabras es una oración, es necesario demostrar que las interpretaciones más sencillas son insuficientes. Pueden considerarse algunos ejemplos en la producción de secuencias por parte de Sara y Lana. Como resultado del entrenamiento, las dos aprendieron mecánicamente a producir secuencias específicas de palabras, por ejemplo, por favor máquina dar manzana (9), o María dar chocolate Sara $(0)$. Posteriormente, tanto Sara como Lana aprendieron a sustituir ciertas palabras por otras nuevas para conseguir del mismo agente, o de otros, nuevos incentivos (por ejemplo, Randy dar Sara manzana, por favor máquina dar bebida o por favor máquina mostrar foto). La última secuencia se ha presentado como una prueba de que Lana había aprendido a utilizar diferentes sverbos» (dar y mostrar) en conjunción con una categoría diferente de incentivos, foto, ventana y música (9).

Las locuciones de varios signos de Sara y Lana pueden interpretarse como consecuencias aprendidas mecánicamente de símbolos dispuestos en órdenes particulares, por ejemplo, Maria dar Sara manzana, o por favor máquina dar manzana. No existen, virtualmente, pruebas de que Lana y Sara comprendieran el significado de todas las epalabras» en las secuencias que producían. Exceptuando los nombres de los objetos que solicitaban, Sara y Lana eran incapaces de sustituir otros símbolos en cada una de las restantes posiciones de las secuencias que habían aprendido. Por consiguiente, sería más prudente considerar las secuencias de símbolos descritos como por favor, máquina, María, Sara y dar como secuencias de símbolos sin sentido (63).

Puede examinarse una actuación comparable, la de las palomas entrenadas para picotear filas de cuatro colores en una secuencia concreta, $\mathrm{A} \longrightarrow \mathrm{B} \longrightarrow \mathrm{C} \longrightarrow \mathrm{D}$, sin tener en cuenta la posición física de los colores (64). En estos experimentos todos los colores se pre. sentaban simultáneamente y no había una retroalimentación paso a paso después de cada res. puesta. La prueba de que los sujetos aprendían la secuencia general y no simplemente las respuestas específicas requeridas por las filas de entrenamiento fue proporcionada por la actuación, considerablemente superior a la esperada por azar, en las filas nuevas. No obstante, queda por demostrar que las palomas puedan dominar los problemas $\mathrm{ABCX}$ (donde $\mathrm{X} 1$ podía referirse a un tipo de grano, $\mathrm{X} 2$ a otro tipo diferente, $\mathrm{X} 3$ al agua, $\mathrm{X} 4$ a la oportunidad de ver $o$ atacar a otra paloma y así sucesivamente). Si una paloma puede aprender estas secuencias (resultado no improbable) uno se pregunta qué se gana al asignar anombres a cada miembro de la secuencia, por ejemplo, referirse a la secuencia verde $\rightarrow$ blanco $\rightarrow$ rojo $\rightarrow$ azul, como máquina dar $R \cdot 42$ grano.

Las secuencias de símbolos producidos por un antropoide pueden parecer, a los ojos de un observador humano, relacionadas gramaticalmente. De esto no se sigue, sin embargo, que el chimpancé tenga algún conocimiento de las relaciones que un observador humano pueda inferir (65). Por difícil que pueda ser entrenar a un antropoide o a cualquier otro organismo, para que produzca una secuencia de respuestas arbitrarias que se asemeje a una oración, es más difícil todavía demostrar que esas secuencias poseen las propiedades estructurales de las oraciones humanas (63). 


\section{Estudios}

\section{Comprensión de las secuencias} de varias palabras

Una dificultad inherente a la utilización de la comprensión aparente como indicador de la competencia sintáctica del niño es la presencia frecuente de indicios no sintácticos en el significado $(22,23)$. Esto puede controlarse diseñando experimentos que excluyan los indicios semánticos y extralingüísticos. Sin embargo, muchos supuestos ejemplos de comprensión de oraciones por los chimpancés pueden explicarse como conductas de solución de problemas no linguiísticos. Incluso los problemas complejos, que parecen requerir un conocimiento de la estructura sintáctica de las instrucciones (por ejemplo, instrucciones condicionales e instrucciones presentadas en forma jerárquica), podrían resolverse aplicando reglas no sintácticas (63).

Las demostraciones de Premack, Rumbaugh y los Gardner de que sus chimpancés pueden responder correctamente a las cuestiones - wh (cuestiones con what (qué), who (quién), where (dónde), etc. N. T.), son una prueba de la capacidad de la memoria de un chimpancé. Sin embargo, no hay base suficiente para concluir que estos chimpancés comprendían las cuestiones - wh. En cada caso, los chimpancés habían ejercitado ampliamente las respuestas correctas a las cuestiones del tipo ¿color eso?: ¿qué eso? y sólo podía elegirse un número limitado de respuestas (generalmente dos). El marco constante en que se administraban problemas repetidos de la misma naturaleza proporcionaba las condiciones ideales para la formación de disposiciones de aprendizaje y la utilización de estrategias no sintácticas en la resolución de estos problemas. Sin una mayor variedad de problemas y un rango mayor de posibles respuestas, los resultados de estos estudios no pueden interpretarse como demostraciones «lingísticas de la comprensión de cuestiones - wh (64).

En su intento de demostrar la comprensión de las cuestiones - wh, los Gardner admitían como correcta cualquier respuesta que hubieran considerado apropiada desde un punto de vista léxico. Por ejemplo, si Washoe contestaba azul a la pregunta ¿qué color? cuando se le mostraba un balón rojo, azul se consideraba «correcta» porque era un color. La correlación significativa que los Gardner encuentran entre las formas de pregunta y respuesta muestra que Washoe aprendió a responder a cuestiones de categorías con signos de la categoría adecuada: colores, nombres de los entrenadores, acciones, y así sucesivamente. Sin embargo, muchas de las respuestas específicas eran claramente inadecuadas. Con todo, los Gardner concluyeron que la actuación de Washoe es comparable a la de un niño en el es- tadio 3 del esquema de Brown de desarrollo del lenguaje en niños (22). En este estadio, los niños no sólo son capaces de responder correctamente a las cuestiones - wh sencillas, sino también de producir cierta variedad de construcciones con una longitud media por encima de los 2,75 morfemas. El sentido del análisis del lenguaje infantil en términos de estadios deriva, en gran parte, de las complejidades estructurales que el niño domina, de forma acumulada; en cada momen. to de su desarrollo. La conclusión de los Gardner no tiene en cuenta estos aspectos del lenguaje infantil en el estadio 3.

\section{Conclusiones}

Los proyectos de enseñanza del lenguaje a chimpacés y gorilas han mostrado que estos antropoides pueden aprender vocabulario de símbolos visuales. Sin embargo, no existen pruebas de que los antropoides puedan combinar dichos símbolos para crear nuevos significados. La función de los símbolos del vocabulario de un antropoide no parece ser tanto identificar cosas o enviar información - por ejemplo, el concepto de Skinner de tacts (66) - como satisfacer una demanda que utilice tal símbolo para obtener algún incentivo -concepto de Skinner de mands (66) -

En nuestro estudio de las más de $20.000 \mathrm{com}$ binaciones de dos o más signos producidos por Nim, un chimpancé de corta edad, examinamos los datos a favor de una estructura sintáctica y semántica. En el caso de las combinaciones de dos signos se observaron regularidades léxicas: determinados signos tendían a aparecer en determinadas posiciones. Es imposible explicar estas regularidades por hábitos generales de posición o por la memorización de muchas secuencias individuales. Por tanto, estas regularidades son una prueba superficial de que las combinaciones de dos signos de Nim seguían reglas de orden de signos. Sin embargo, otros aspectos de la utilización del lenguaje de signos por Nim hacen pensar que es aventurado concluir que sus combinaciones son aoraciones primitivas.

La longitud media de las combinaciones de Nim oscilaba entre 1,1 y 1,6 durante los diecinueve últimos meses del proyecto. Durante ese tiempo, su vocabulario se duplicó con creces (de 42 a 125 signos). Las combinaciones de tres signos de Nim no mostraron ninguna regularidad léxica, ni elaboraron o cualificaron lo que emitía con combinaciones de dos signos.

Nuestro análisis semántico de las combinaciones de dos signos de Nim mostró que el 85 por 100 podían adscribirse sin ambigüedad a una categoría entre veinte. Sobrepasando los re- 
sultados de otros estudios, demostramos la fiabilidad de nuestros juicios semánticos y también observamos que ciertos roles semánticos se expresaban en un orden determinado de signos. Sin embargo, nuestros resultados también sugieren que es prematuro aplicar el método de la «interpretación amplia a las locuciones de un antropoide. No sólo parece el número de ejemplos léxicos de cada rol semántico demasiado escaso para justificar que las regularidades en el orden se consideren semánticas (en vez de léxicas), sino que también existían demasiadas regularidades en el orden de las combinaciones de determinados signos. Por tanto, no hay datos suficientes para demostrar el conocimiento de las reglas de categorías semánticas.

El análisis del diálogo, que relacionaba las soluciones del lenguaje de signos de $\mathrm{Nim}$ con la utilización inmediatamente anterior del lenguaje de signos por su maestro, proporcionó una base adicional para afirmar que el lenguaje de signos de Nim era diferente, en lo fundamental, al lenguaje infantil. Nim imitaba e interrumpía las locuciones de su maestro con mucha mayor frecuencia que el niño el lenguaje del adulto. De aquí se deduce que Nim era menos creativo en la producción de locuciones que un niño y que no había aprendido el toma y daca de la conversación que es evidente en el uso temprano del lenguaje infantil. Los análisis de las películas de otros antropoides emitiendo signos con sus maestros reveló una falta similar de creatividad en otras locuciones de los antropoides y una de- pendencia similar de estas locuciones de los signos anteriores de sus maestros.

En suma, las pruebas de la producción de oraciones por los antropoides pueden explicarse, en cada caso, mediante procesos no lingüisticos más sencillos. Las secuencias de signos de Nim y otros antropoides pueden parecerse, superficialmente, a las primeras secuencias de varias palabras emitidas por los niños. Pero mientras no se eliminen las explicaciones alternativas de las combinaciones de signos de los antropoides, particularmente el hábito de imitar en parte las locuciones anteriores de los maestro, no hay razones para considerar que las locuciones de varios signos de los antropoides son oraciones.

Nuestros resultados indican con firmeza que cualquier nuevo estudio de la capacidad de uso del lenguaje por los antropoides debe recolectar un amplio corpus de locuciones, en contextos que puedan remitirse con facilidad a un registro visual permanente (67). Sin estos datos, tendriamos una base incompleta para comparar el uso del lenguaje en los niños y los antropoides.

De momento, nuestra investigación detallada sugiere que el aprendizaje del lenguaje por los antropoides posee severas restrinciones. Pueden aprender muchos símbolos aislados (lo mismo que los perros, los caballos y otras especies no humanas), pero no demuestran un dominio inequívoco de la organización conversacional, semántica o sintáctica del lenguaje.

\section{Referencias}

1. B. T. GARDNER y R. A. GARDNER, J. Exp. Psychol. Gen. 104 (No. 3), 244 (1975).

2. R. A. GARDNER y B. T. GARDNER, Ann. N. Y. Acad. Sci. 309, 37 (1978).

3. -, ibid. 187, 752 (1975).

4. D. PREMACK, Science 172, 808 (1971).

5. -, J. Exp. Anal. Behav. 14, 107 (1970)

6. -, Intelligence in Ape and Man (Lawrence Erlbaum Associates, Hillsdale, N. J., 1976)

7. J. C. WOODW ARD, Sign Lang. Stud. 3 , 39 (1973); H. BORNSTEIN en Sign Language of the Deaf: Psychological, Linguistics and Sociological Perspectives, I. M. SCHLESINGER y L. NAMIR, Eds. (Academic Press, New York, 1978), pp. 338-361; W. C. Stokoe et al. (8). A menudo se supone, erróneamente, que todas las formas de comunicación visual-manual son ASL. Sin embargo, los lenguajes de signos varían a lo largo de un continuo. En un extremo se encuentra el ASL, que posee una gramática única, dispositivos expresivos y morfología. El ASL, lengua natural de los sordos americanos, es el primer lenguaje de muchos de ellos, especialmente de los niños sordos hijos de padres sordos. En el extremo opuesto se encuentra el Signed English, que es un código de expresión del inglés en un sisterma manual-visual. En el Signed English - y no en el ASL - los signos siguen el orden de palabras inglés, hay algunos que equivalen a mordemas como ed y -ly. En el Pidgin Sign English (PSE), se utilizan los signos del ASL junto con alguno de sus dispósitivos expresivos, sin los morfemas gramaticales del inglés. Las personas con audición normal rara vez alcanzan el anivel nativos en el control de la compleja gramática y estructura del ASL. En este y en todos los 


\section{Estudios}

restantes estudios de enseñanza de signos a los antropoides se utilizó el PSE y no el ASL. En este sentido es equívoco denominar su signos como ASL, puesto que no exhiben la estructura gramatical de este lenguaje.

8. W. C. STOKOE, JR., D. C. CASTERLINE, C. C. CRONBERG. Eds., A Dictionary of American Sign Language on Linguistic Principles (Galludet College Press, Washington, D. C., 1965).

9. D. M. RUMBAUGH, Ed., Language Learning by a Chimpanzee: The Lana Project (Academic Press, New York, 1977)

10. R. S. FOUTS, J. Comp Physiol. Psychol. 80, 515 (1972); M. K. TEMERLIN, Lucy: Growing Up Human (Science and Behavior Books, Palo Alto, Calif., 1975).

11. F. G. PATTERSON, Brain Lang. 12, 72 (1978).

12. P. LIEBERMAN, Ann. N. Y. Acad. Sci. 280, 660 (1975)

13. C. HAYES, The Ape in Our House (Harper \& Row, New York, 1951); K. J. HAYES y C. HAYES. Proc. Am. Philos. Soc. 95, 105 (1951); W. N. KELLOGG, Science 162, 423 (1968); -, y L. A. KELLOGG, The Ape and the Child (McGraw-Hill, New York, 1933); N. N. LADYNA-KOTS, Infant Ape and Human Child (Museum Darwinianum, Moscow, 1935), vol. 1.

W. H. THORPE, Bird Song (Cambridge Univ. Press. London, 1961); K. VON FRISH, The Dancing Bees (Methuen, London, 1954); N. TINBERGEN, The Study of Instinct (Claredon, Oxford, 1951).

14. N. CHOMSKY, Aspects of the Theory of Syntax (MIT Press, Cambridge, Mass, 1965); Syntactic Structure (Mouton, The Hague, 1957); M. GROSS, M. HALLE, M. P. SCHUZTENBERGER, Eds. The Formal Analysis of Natural Languages (Mouton, The Hague, 1973); J. KATZ y P. M. POSTAL, An Integrated Theory of Linguistic Description (MIT Press, Cambridge, Mass., 1964).

16. Nim nació el 21 de noviembre de 1973 en el alnstitute for Primate Studies» en Norman, Oklahoma. El 2 de diciembre de 1973 llegó a Nueva York, acompañado por Mrs. Stephanie LaFarge, quien, con su familia, crió a Nim en su casa del West Side, en Nueva York, durante veintiún meses. Entre el 15 de agosto de 1975 y el 25 de septiembre de 1977, Nim vivió en una gran casa con jardín, propiedad de una universidad estatal (Delafield) en Riverdale, N. Y.; allí era criado por cuatro o cinco entrenadores residentes. Nim desarrolló un apego especialmente fuerte hacia ciertos miembros del proyecto. $\mathrm{H}$. S. Terrce fue el único miembro del proyecto que mantuvo un lazo fuerte y continuo con Nim durante el proyecto. En los dieciocho primeros meses, Mrs. LaFarge fue la persona más importante en la vida de Nim. Después del traslado a Delafield, Nim se apegó estrechamente a L. A. Petitto, que supervisó su crianza en Delafield y en un aula especial construida para Nim en el Departamento de Psicología de la Universidad de Columbia. Después de separarse Petitto del proyecto (cuando Nim tenía treinta y cuatro meses), Nim desarrolló un fuerte apego hacia dos maestros residentes en Delafield, W. Tynan y J. Butlet. Desde septiembre de 1974 hasta agosto de 1977. Nim acudía a su clase en Columbia de tres a cinco veces por semana; allí recibía una enseñanza intensiva de la expresión de signos y podía set observado, fotografiado y grabado en video por los otros maestros sin grandes distraciones (a través de un cristal unidireccional). Nim también recibió clases en Delafield, aunque de un modo más informal. El análisis detallado de los signos en Delafield y en la clase de Columbia no mostró diferencias sistemáticas en ninguno de los aspectos, expuestos en este informe, de la producción de signos de Nim. Durante los cuarenta y seis meses que vivió en Nueva York, Nim tuvo sesenta maestros voluntarios, no permanentes. Según crecía, las reacciones emocionales de Nim ante los cambios de personal se intensificaron y el atraer la atención de Nim se volvió progresivamente más difícil para los nuevos maestros. Hacia septiembre de 1977 , se vio con claridad que no había recursos para manetener un equipo permanente de maestros cualificados que pudiera hacer progresar los aspectos científicos del proyecto. Nuestra alternativa era contratar cuidadores que pudieran hacerse cargo de Nim, pero que no estaban cualificados uniformemente para comprender el lenguaje de signos de Nim, o dar por finalizado el proyecto. Con gran disgusto, nos decidimos por lo último. El 25 de septiembre de 1977, Nim volvió a su lugar de nacimiento en Oklahoma. La descripción completa de la historia de Nim y su socialización puede encontrarse en (17).

17. H. S. TERRACE, Nim (Knopf, New York, 1979).

18. R. S. FOUTS y L. GROODIN, Bull. Psychom. Soc. 4 (No. 4a), 264 (1974).

19. L. BLOOM, Language Development: Form and Function in Emerging Grammars (MIT Press, Cambridge, Mass., 1970).

20. - One Word at a Time: The Use of Single Word Utterances Before Syntax (Mouton, The Hague, 1973)

21. L. BLOOM y M. LAHEY, Language and Development and Language Disorders (Wiley, New York, 1978).

22. R. BROWN, A First Language: The Early Stages (Harvard Univ. Press. Cambridge, Mass., 1973).

23. J. A. FODOR, T. G. BEVER M. F. GARRETT, The Psychology of Language (McGraw-Hill, New York, 1978).

24. M. BRAINE, Monogr. Soc. Res. Child Dev. 41 (1), Serial No. 164 (1976).

25. Signo imitativo es el que repite la locución inmediatamente antetior del maestro. Signo espontáneo es el que no aparece en la locución inmediatamente anterior del maestro. Un signo inducido («prompteds) es el que sigue a una ayuda del maestro. Una ayuda utiliza sólo una parte de la configuración característica del signo, del movimiento, o de su localización. Por ejemplo, el maestro podía inducír el signo Nim (los dedos pulgar e índice extendidos hacia abajo en la sien) sacando estos dos dedos del puño. El acuerdo entre los informes de los maestros y los registros de un juez independiente (que observaba a Nim y a sus maestros a través del cristal unidireccional del aula de Columbia o bien transcribía las cintas video) oscilaba entre el 77 y el 84 por 100 . Prácticamente todos los desacuerdos tuvieron lugar cuando el maestro no registraba un sig. no; por ejemplo, cuando el maestro estaba ocupado preparanda una actividad, o cuando Nim realizaba los signos muy rápidamente, o cuando eta el maestro quien producía los signos. No parece que las omisiones 
del maestro fueran sistemáticas. En el peor de los casos, los informes de los maestros estimaban por bajo la emisión de signos de Nim.

26. Puede encontrarse un listado completo del vocabulario de Nim, incluidos el contexto en que ocurría cada signo y su topografía en (17, Apéndice C).

27. B.T. GARDNER y R. A. GARDNER, Bull Pychon, Soc. 4 (No. 4a), 264 (1974); Minn. Symp. Child Psychol, 8, 3 (1974).

28. El orden de las palabras no es más que una de las formas en que una lengua puede codificar diferentes sig. nificados. Sin embargo, cuando puede demostrarse la existencia de regularidades en el orden de los signos, existe una base fuerte para suponer la existencia de una extructura gramatical. Dada la dificultad de documentar otros aspectos de los signos de los antropoides, las regularidades en el orden de los signos pueden set la forma más sencilla de demostrar que las locuciones de un antropoide son gramaticales. U. BELLUGI y E. S. KLIMA. The Signs of Language (Harvard Univ. Press, Cambridge, Mass., 1979); H. W. HOEMANN, The American Sign Language: Lexical and Grammatical Notes with translation Exercises (National Association of the Deaf, Silver Spring, Md., 1975); E. S. KLIMA y U. BELLUGI, Ann. N. Y. Acad. Sci. 263, 255 (1975); H. LANE, P. BOYES-BRAEM, U. BELLUGI, Cog. Psychol. 8, 262 (1976).

29. En el ASL, la segmentación de las combinaciones en signos tiene una función semejante a la segmentación de las frases en palabras, propia del lenguaje hablado: la segmentación delimita las secuencias de signos que están relacionadas inmediatamente entre sí. También se utilizan otros dispositivos de segmentación en el ASL; además de abrir las manos, los cambios específicos de la cabeza y el cuerpo, y las expresiones faciales específicas señalan los límites elementales. STOKOE et al., (8); E. BROWN y S. MIRON, J. Verbal Learn. Verbal Behav. 10, 658 (1971); H. LANE y F. GROSJEAN, J. Exp. Psychol. 97, 141 (1973).

30. En las combinaciones de signos que se repetían sucesivamente se utilizaron dos teglas. Estas proporcionaban la descripción más breve de una combinación particular. Las combinaciones homogéneas, si todos los signos de la secuencia eran idénticos (comer comer comer), se consideraban como una locución de un sólo signo (comer). Las secuencias homogéneas de signos no se tabulaban como combinaciones. En las secuencias heterogéneas, si se repetía un signo determinado, no se contaban las repeticiones que iban seguidas. En la tabulación del corpus, una secuencia como plátano a mí a mí a mí comer quedaba reducida a plátano a mí comer. Mientras la secuencia original contenía cinco signos, esta combinación se tabulaba como una secuencia de tres signos. Como regla general, el signo $Y$, repetido $n$ veces sucesivas, se contabilizaba como una única aparición de $Y$, cualquiera que fuera el valor de $n$. Las entradas de la Tabla 1 representan el número de tipos y de muestras de las combinaciones lineales de Nim, tal como se observaban, antes de aplicar las reglas de reducción. El listado completo de las combinaciones de Nim después de aplicat estas reglas, puede encontrarse en Terrace $e t$ al. (3I). En ASL, la repetición de signos conlleva significados particulares. Un ejemplo de un tipo de contraste entre signos repetidos y no repetidos es la diferencia entre las formas de ciertos nombres y verbos. Muchos verbos (barrer, volar, conducir) consisten en un sólo movimiento; en los nombres relacionados (escoba, avión, coche) se repite el signo dos veces (la denominada forma de rebote; véase T. Suppala y E. Newport, comunicación personal). Ninguno de los maestros de Nim podía distinguir entre los significados de las locuciones que contuvieran o no signos repetidos sucesivamente. Su única función parece ser el énfasis. En general, menos del 15 por 100 de las locuciones lineales que observamos contenían signos repetidos sucesivamente. Por lo que hemos podido ver, los resultados de nuestro análisis no habrían cambiado si hibiéramos incluido locuciones con signos repetidos sucesivamente.

31. H. S. TERRACE. L. A. PETITTO, R. J. SANDERS, T. BEVER, en Children's Language, K. NELSON, Ed. (Gardner Press, New York, in press), vol. 2.

32. Otros listados completos de las regularidades en las combinaciones de los signos de Nim pueden consultarse en (17).

33. El hecho de que a mí aparezca más veces que Nim en las combinaciones de dos signos puede, quizás, explicarse mejor por haber aprendido Nim el signo a mí antes que el signo Nim. Posteriormente, las frecuencias con que se combinan los verbos transitivos con Nim y a mi fueron esencialmente iguales. En el caso de las combinaciones con más, podría argumentarse que Nim imitó la combinación más $+X$ de las locuciones de sus maestros. Frecuentemente un maestro realizaba los signos más $+X$, para ver si Nim replicaba más o $X$. Según este punto de vista, Nim aprendió a emitir más $+X$ por imitación de unos cuantos casos de más + $X$ y una generalización posterior de esta construcción hacia nuevos objetos y acciones. Tal generalización sería necesaria porque Nim producía la mayoría de las primeras muestras de cada tipo de combinación más $+X$ sin ningún modelado del maestro. Este tipo de explicación parece menos adecuado en el caso de otras clases de combinaciones, por ejemplo, las que contienen verbos transitivos en la Tabla 2, puesto que no se planteó a Nim ninguna cuestión con estos signos, que hubieran podido servirle de modelo.

34. N. COLBURN, tesis, Teachers College, Columbia University (1979).

35. La mayoría de las comparaciones que haremos se basan en los datos obtenidos de los estudios de adquisición del lenguaje hablado en niños y padres con audición normal. Los maestros que enseñaron a Nim tenían audición normal y no eran diestros en el lenguaje de signos. Por consiguiente, los estudios que describen la adquisición del lenguaje de signos por niños sordos con padres normales constituirían el punto de referencia más pertinente para evaluar los datos que obtuvimos con Nim. Sin embargo, los datos asequibles, hasta el momento, de los niños sordos (de padres sordos o con audición normal) indican que no hay diferencias importantes entre los rasgos generales de la adquisición del lenguaje por los niños sordos o de audición normal. Para más detalles, véase (36-38).

36. E. F. ASHBROOK, Development of semantic relations in the acquisition of American Sign Language, (working paper. Salk Institute, June 1975). 


\section{Estudios}

37. R. S. HOFMEISTER, Proceedings of the First National Symposium on Sign-Language Research and Teaching, Chicago, 1977.

38. E. S. KLIMA y U. BELLUGI en Communication and Affect: A Comparative Approach, T. ALLOWAY, L. KRAMES, P. PLINER. Eds. (Academic Press, New York, 1972), p. 67.

39. Al calcular la LML de un niño, se siguen ciertas convenciones que no pueden aplicarse directamente a las secuencias de signos. Las locuciones habladas, por ejemplo, se dividen a menudo en morfemas y no en palabras: running y run there se considerarían locuciones de dos morfemas. En el lenguaje de signos, la locución run there puede expresarse por un único signo -E. S. Klima y U. Bellugi (38)-. Aunque todavía debe calibrarse la LML como medida del desarrollo lingüistico en los lenguajes de signos, es interesante, sin embargo, plantearse cómo variaba la longitud media de las combinaciones durante el tiempo en que regis. tramos sus locuciones. Las reglas utilizadas en el cálculo de la LML son una adaptación parsimoniosa de las reglas de Brown (22). Véase Terrace et al. (31) para más detalles.

40. Que nosotros sepamos, las únicas curvas descritas hasta ahora de la LML en niños sordos que adquieren el lenguaje de signos son las de E. S. Klima y U. Bellugi (38); H. S. Schlesinger, en preparación; R. J. Hoffmeister (37). Puede explicarse el retraso aparente en el crecimiento de la LML en los niños sordos por la propiedad del lenguaje de signos de codificar cierto número de morfemas en un signo único -véase $\mathrm{E}$. S. Klima y U. Bellugi (38), pág. 85-.

41. R. BROWN, comunicación personal.

42. J. M. SCHLESINGER, en Ontogenesis of Grammar, D. I. SLOBIN, Ed. (Academic Press, New York, 1971), p. 63.

43. En algunos casos, el orden de las palabras servía de contraste y al menos en un niño se observaron diferen. cias de entonación asociadas a diferencias de significado. L. BLOOM (20); M. BOWERMAN, Early Syntactic Development: A Cross-Linguistic Study with Special Reference to Finnish (Cambridge Univ. Press. London, 1973.

44. B. T. GARDNER y R. A. GARDNER en Behavior of Nonhuman Primates: Modem Research Trends, A. M. SCHRIER y F. STOLINITZ, Eds. (Academic Press, New York, 1971), vol. 4, pp. 117-184.

45. R. S. FOUTS, en Society and Psychology of Primates, R. H. TUTTLE, Ed. (Mouton, The Hague, 1975), pp. 371-390.

46. El corpus semántico comprendía datos de unos cinco meses y medio de cada maestro. Los datos se basaban en 48 informes de J. Butler, 58 de R. Sanders y 41 de W. Tynan. Después de interpretar las locuciones de sus propias sesiones, cada maestro interpretaba las locuciones de uno o de los restantes maestros. Estuvieron de acuerdo en la interpretación de 717 locuciones ( 57 por 100 del corpus original). Si no podía resolverse el desacuerdo, la locución se descartaba por ambigua. Las notas contextuales de los informes de los maestros incluían información suficiente para que los maestros coincidieran en la interpretación de las 967 combinaciones de dos signos ( 76 por 100 del corpus original). En los casos restantantes $(N=295)$, o no pudo darse una interpretación adecuada $(\mathrm{N}=260)$, o había dos interpretaciones igualmente razonables, sin que pudiera descartarse una $(\mathrm{N}=35)$. Estas combinaciones no se incluyen en nuestro análisis. Ninguna de nuestras conclusiones cambiaría si utilizáramos alguna de las interpretaciones de las combinaciones no descartables.

47. R. BROWN, Psycholinguistics: Selected Papers by Roger Brown (Free Press, New York, 1970).

48. El número de categorías utilizadas en la interpretación de las primeras combinaciones de un niño o de un antropoide es arbitrario. Nuestras 20 categorías podían reducirse a siete en el sistema de Brown, quedando excluidas dos; a ocho en el de los Gardner, con dos excluidas, y a 11 en el de Patterson, con una excluida.

49. Además de las combinaciones de relación que observamos (Fig. 3), se asignaron interpretaciones que no eran de relación a 166 combinaciones que aparentemente expresaban la conjunción de elementos de dos proposiciones, por ejemplo, cosquillear abrazo, sucio correr, manzana,nuez y dentro juego. Estas expresiones son raras en el lenguaje infantil y no se han especificado en edtudios anteriores de aprendizaje del lenguaje de signos por los antropoides. L. BLOOM, P. LIGHTBOWN, L. HOOD, Monogr. Soc. Res. Child Dev. 40 (2). Serial No. 160 (1975).

50. E. NEWPORT, en Cognitive Theory, N. J. CASELLAN. D. B. PISONI, G. R. POTTS, Eds. (Lawrence Erlbaum Associates, Hillsdale, N. J., 1976); C. SNOW, Child Dev. 43, 549 (1972).

51. L. BLOOM, L. ROCISSANO, L. HOOD, Cog. Psychol, 8, 521 (1976).

52. C. FILMORE, On Deixis (Indiana Linguistics Club, Bloomington, 1973), vol. 9, p. 269.

53. D. STERN, J. JAFFEE, B. BEEBE, S. BENNETT, Ann. N. Y. Acad. Sci. 263, 89 (1975).

54. Estos análisis los realizó R. J. Sanders. El maestro que trabajaba con Nim transcribía cada cinta (L. Petitto, cuatro cintas; R. Sanders, cuatro cintas; J. Butler, una cinta; W. Tynan, una cinta). En nuestro análisis del diálogo sólo utilizamos signos aislados y combinaciones lineales; ambos daban cuenta del 95 por ciento de las locuciones transcritas. Un examen informal del 5 por 100 restante (combinaciones simultáneas y contracciones) indicó que los resultados seguirían siendo los mismos aunque se incluyeran en el análisis todas las locuciones de Nim. Para calcular la fiabilidad de nuestras transcripciones, dos maestros del proyecto transcribieron por separado segmentos cortos de cinco cintas. El acuerdo medio entre los dos fue del 81,8 por ciento.

S4a. M. McINTYRE \&Learning to take your turn in ASLs, manuscrito no publicado.

55. L. BLOOM, comunicación personal.

56. U. BELLUGI, comunicación personal.

56a. C. BAKER - en On The Other Hand: New Perspectives on American Sign Language, L. A. FRIEDMAN, Ed. (Academic Press, New York, 1977) - señala que, en algunos casos, el signo del thablantes se solapa con el signo del ıdestinatario; por ejemplo, cuando se mantiene momentáneamente el último signo de 
una pregunta. Sin embargo, Baker (comunicación personal) observa que esta clase de solapamiento no se considera interrupción y que las interrupciones de las parejas de interlocutores en los lenguajes de signos son tan infrecuentes como en el lenguaje oral.

57. The First Signs of Washoe, WGBH Time-Life, Nova (Time-Life Films, New York, 1976).

58. Teaching Sign Language to the Chimpanzee: Washoe, producido por R. A. GARDNER y B. T. GARDNER (Psychological Cinema Register, University Park, Pa., 1973), No. 16802.

59. - Las transcripciones del diálogo de Washoe y sus maestros (Tablas 6 a 9) fueron preparadas por L. A. Petitto y verificadas por $\mathrm{H}$. S. Terrace. Al preparar las transcripciones seguimos la práctica de los psicólogos y lingüístas que estudian la adquisición del lenguaje de signos en niños sordos, examinando cada locución a velocidad normal y a cámara lenta. Es obvio que las descripciones estáticas de los signos aislados (Tablas 6 a 9 y Figs. 5 y 6) no pueden proporcionar información sobre el movimiento. Esta información sería crucial, por ejemplo, para distinguir aquellos signos en que la repetición influye en su significado - signos de arebote», descritos en (30)- El examen de las dos películas no descubrió ningún caso en que, al añadirse la información sobre el movimiento, se alterara la interpretación de los signos de Washoe o de sus maestros. Salvo la excepción señalada en la Tabla 7 y la Fig. 5, los segmentos que analizamos no presentaban empalmes. Nuestras transcripciones y dibujos muestran todos los signos de Washoe y el maestro, y el tiempo en que se aparecían en los segmentos que seleccionamos. Puesto que en las películas que analizamos se habían montado distintos segmentos, no pudimos establecer una referencia temporal común para la aparición de cada signo. En las transcripciones, el tiempo de aparición de cada signo se especificó respecto al del primer signo de esa parte de la transcripción (designado arbitrariamente 00.00). El tiempo se midió contando el número de cuadros entre el comienzo de cada escena. Los números de los cuadros en la transcripción hacen referencia a los cuadros de las figuras de este texto en que hay un dibujo del signo. En las Tablas 6 y 9, las barras inclinadas indican el principio y el final de cada locución. Las restantes conductas se describen entre parén. tesis. Los dibujos fueron realizados por L. Roberts.

60. Los Gardner no han presentado pruebas de que Washoe comprendiera el significado del signo time (tiem. po, hora). En este y en otros ejemplos de su utilización da la impresión de que Washoe había aprendido que era una respuesta apropiada para pedir alimento o algún otro incentivo (descripción de los Gardner del uso del tiempo (1, págs. 266).

61. P. S. DALE, Language Development, Structure and Function (Holt Rinehart \& Winston, New York, 1976).

62. T. G. BEVER, en Georgetown University Round Table on Languages and Linguistics, D. P. DATO, Ed. (Georgetown Univ. Press, Washington, D. C., 1975), pp. 63-75.

63. H. S. TERRACE, J. Exp. Anal. Behav. 31. 161 (1979).

64. -, Bull, Psychon. Soc. 9, 269 (1977); R. O. STRAUB, M. S. SEIDENBERG, T. G. BEVER, H. S. TERRACE, J. Exp. Anal. Behav. 32, 137 (1979); R. O. STRAUB, tesis, Columbia University (1979).

65. J. LIMBER, Am. Psychol, 32 (No. 4), 280 (1977); G. MOUNIN, Cum. Anthropol, 17 (No. 1). I (1976); M. S. SEIDENBERG y L. A. PETITTO, Cognition 7, 177 (1979).

66. B. F. SKINNER, Verbal Behavior (Appleton-Century-Crofts, New York, 1975).

67. Nuestra experiencia permite suponer que, para conseguir un dominio del lenguaje de signos superior al que hemos observado en Nim, es importante garantizar que un grupo pequeño y estable de maestros -véase (17) - crie y enseñe al sujeto de este tipo de estudios.

68. Trabajo financiado parcialmente por las becas de la W. T. Grant Foundation, la Harry Frank Guggenheim Foundation y NIH (ROL MH29293). Agradecemos a L. Bloom y a R. Brown sus valiosos comentarios a una versión preliminar de este informe; a S. Lafarge la atención con que crió a Nim durante los dieciocho primeros meses; a B. Stark, S. Lerman y T. Blumenfeld la supervisión y el cuidado médico de Nim, y a G. A. Tate la asistencia y las fotografías de Nim. También queremos dar las gracias a los más de 100 voluntarios que trabajaron con Nim y en el análisis de datos, y a W. Benesch, I. Brody, J. Butler, B. Johnson, S. Quimby, A. Schachter y W. Tynan su ayuda. 